NBER WORKING PAPER SERIES

\title{
HOW DO HOUSE PRICES AFFECT CONSUMPTION? EVIDENCE FROM MICRO DATA
}

\author{
John Y. Campbell \\ João F. Cocco \\ Working Paper 11534 \\ http://www.nber.org/papers/w11534
}

\author{
NATIONAL BUREAU OF ECONOMIC RESEARCH \\ 1050 Massachusetts Avenue \\ Cambridge, MA 02138 \\ August 2005
}

We would like to thank David Laibson and seminar participants at Harvard, the London School of Economics, and the 2004 SED meetings for comments. We are particularly grateful to an anonymous referee for detailed and constructive comments. The views expressed herein are those of the author(s) and do not necessarily reflect the views of the National Bureau of Economic Research.

(O2005 by John Y. Campbell and João F. Cocco. All rights reserved. Short sections of text, not to exceed two paragraphs, may be quoted without explicit permission provided that full credit, including $\odot$ notice, is given to the source. 
How Do House Prices Affect Consumption? Evidence From Micro Data

John Y. Campbell and João F. Cocco

NBER Working Paper No. 11534

August 2005

JEL No. D1, G1

\section{ABSTRACT}

Housing is a major component of wealth. Since house prices fluctuate considerably over time, it is important to understand how these fluctuations affect households' consumption decisions. Rising house prices may stimulate consumption by increasing households' perceived wealth, or by relaxing borrowing constraints. This paper investigates the response of household consumption to house prices using UK micro data. We estimate the largest effect of house prices on consumption for older homeowners, and the smallest effect, insignificantly different from zero, for younger renters. This finding is consistent with heterogeneity in the wealth effect across these groups. In addition, we find that regional house prices affect regional consumption growth. Predictable changes in house prices are correlated with predictable changes in consumption, particularly for households that are more likely to be borrowing constrained, but this effect is driven by national rather than regional house prices and is important for renters as well as homeowners, suggesting that UK house prices are correlated with aggregate financial market conditions.

John Y. Campbell

Department of Economic

Littauer Center 213

Harvard University

Cambridge, MA 02138

and NBER

john_campbell@harvard.edu
Joao F. Cocco

London Business School

Regent's Park

London NW1 4SA

UNITED KINGDOM

jcocco@london.edu 


\section{Introduction}

Housing is the dominant component of wealth for the typical household in the United States or the United Kingdom. Bertaut and Starr-McCluer (2002) show that residential property accounted for about one quarter of aggregate household wealth in the US in the late 1990's, while Banks and Tanner (2002) report that real estate accounted for 35\% of aggregate household wealth in the UK in the mid 1990's. Housing wealth is particularly important for middle-class households: Tracy and Schneider (2001), for example, show that it accounts for almost two-thirds of the wealth of the median US household. The share of housing is likely to be even higher today after several years of strong house price growth.

Houses are risky assets with volatile prices. Much of this volatility is local, but there is a common component to house prices that is visible in regional and even national house price indexes. National house price volatility is particularly striking in the UK, a geographically compact country with a nationally integrated housing market. Figure 1 shows the evolution of house prices in the United Kingdom between 1988 and 2000, a period in which annual changes in nominal house prices ranged from $-10 \%$ to $30 \%$.

The magnitude and volatility of housing wealth have led many to suggest that house price changes have significant effects on aggregate consumption. Muellbauer and Murphy (1990), for example, argued that house price increases and financial liberalization stimulated a consumption boom in the UK in the late 1980's. More recently Case, Quigley, and Shiller (2003) find a strong correlation between aggregate house prices and aggregate consumption in a panel of developed countries from the late 1970's through the late 1990's. (See also Benjamin, Chinloy, and Jud 2004 and Bhatia 1987.)

It is tempting to attribute the correlation between house prices and consumption to a direct housing wealth effect: Increasing house prices increase housing wealth, which in turn increases consumption. There are, however, several reasons not to make this attribution without further analysis. First, the theoretical rationale for

a large housing wealth effect is unclear. If we define financial wealth as the sum of liquid financial assets and the value of real estate minus debt outstanding, it is clear that an increase in house prices leads to an increase in homeowners' financial wealth. But this does not necessarily mean that their real wealth is also higher. Housing is a consumption good, and for a homeowner who expects to live in his current house for a 
very long time, a higher house price is simply compensation for a higher implicit rental cost of living in the house. In other words, as Sinai and Souleles (2005) point out, homeowners with a long expected tenure are perfectly hedged against fluctuations in rents and the corresponding fluctuations in house prices. These fluctuations, however large they may be, have no real wealth effect, and absent any substitution effects, should not affect consumption choices.

Second, there are alternative explanations for the correlation between house prices and consumption. House prices may affect consumption by relaxing or tightening borrowing constraints. Housing is an asset that can be used as collateral in a loan. For borrowing constrained homeowners, an increase in house prices relaxes borrowing constraints, even if there is no wealth effect associated with the house price increase. In other words, an increase in house prices may lead to an increase in consumption not because of a wealth effect, but because it allows borrowing constrained homeowners to smooth consumption over the life cycle (Ortalo-Magné and Rady 2001, Lustig and van Nieuwerburg 2004).

It is also possible that the correlation between house prices and consumption may be driven by an unobserved macroeconomic factor. For example house prices may respond to future income prospects, to which current consumption also responds provided that households are not borrowing constrained. In other words, when households become optimistic about the economy as a whole, the price of housing increases along with consumption (King 1990). Alternatively, financial liberalization may drive up house prices and stimulate consumption by relaxing borrowing constraints on all consumers (Attanasio and Weber 1994, Muellbauer and Murphy 1997).

The objective of this paper is to use household level data to distinguish among these alternative explanations for the house price-consumption correlation. Micro data can be helpful in several ways. First, micro data allow us to identify those households for which the direct wealth effect of house prices is particularly large or small. Most young households plan to increase house size later in life, say because of an expected increase in family size, and for this reason can be thought of as "short" in housing. On the other hand, many old households plan to move to a smaller house later in life, so they are "long" in housing. Without instruments that allow households to insure these short and long positions, there is a redistributive wealth effect of unexpected shocks to house prices. We expect to see older homeowning households increasing their consumption when house prices rise, while younger renting households should cut their consumption. 
Second, micro data allow us to distinguish the effects of local and national movements in house prices. National income prospects and financial liberalization operate through national house prices, while regional income prospects, direct wealth effects, and collateral effects operate through local house prices.

In our analysis of household level data, we also distinguish between predictable and unpredictable movements in house prices and consumption. This approach, which we borrow from the literature testing the permanent income hypothesis (Hall 1978, Hall and Mishkin 1982, Flavin 1981, Campbell and Mankiw 1989, 1991, Zeldes 1989a, Runkle 1991), enables us to distinguish wealth effects from other effects such as collateral effects, precautionary savings, or myopic behavior.

We use household level data from the UK Family Expenditure Survey (FES) to estimate the response of consumption to house prices. The FES is a continuous survey of households, in which each household is interviewed only once. Therefore we employ the methodology introduced in Browning, Deaton, and Irish (1985) and Deaton (1985) to construct panel data from a time-series of cross-sections, or a pseudo-panel. The use of household level data are important because we can estimate the response of consumption to house prices in the region where the household lives, and control for changes in household income, the degree of household leverage, and household demographics. We make use of the fact that households are heterogeneous along several dimensions, including age, homeownership status, and region of residence, to at least partially distinguish between aggregate, regional, and household specific effects of house prices on household consumption.

The use of pseudo-panel data limits our analysis in certain ways. With such data we are not able to precisely identify those households for whom the wealth effect of house price changes is largest, or for whom borrowing constraints are relaxed when house prices increase. We can only uncover how likely a person in a given cohort is to experience a wealth effect due to house price changes, or how likely is it that a person in a given cohort is borrowing constrained. In addition, pseudo-panel data is likely to include substantial measurement error.

With these limitations in mind, we find considerable heterogeneity in the response of household consumption to house prices. More precisely, we estimate a large positive effect of house prices on consumption for the cohort of old households who are homeowners, and an effect that is close to zero for the cohort of young households who are renters. These are the cohorts of households who are most likely to be long and short in housing, respectively. The estimated house price elasticity of consump- 
tion is as large as 1.7 for the old homeowners group, controlling for interest rates, household income, and other demographic variables. This age heterogeneity is important since it suggests that as the population ages and becomes more concentrated in the old homeowners group, aggregate consumption may become more responsive to house prices. Previous estimates of the elasticity of consumption to house prices using aggregate data miss this source of time variation since they do not take into account the slowly changing age structure of the population. However, one should bear in mind that changing demographics may have general equilibrium effects on the stochastic processes for production factors and house prices, and the decision rules of households.

Controlling for economy-wide house prices and for regional income, we find that regional house prices have important effects on household consumption. In fact, the estimated elasticity of consumption with respect to regional house prices is larger than the estimated elasticity with respect to UK house prices when we include both in the regression together with regional income. This shows that it is important to consider regional heterogeneity when estimating the effects of house prices on consumption.

Finally, we find that consumption responds to predictable changes in house prices, an effect which is consistent with an increase in house prices relaxing borrowing constraints, but that may also be explained by a precautionary savings motive or by myopic household behavior. The effect appears to be weaker among homeowners with positive home equity, who have unused borrowing capacity. However, since predictable changes in aggregate and not regional house prices matter, and since the consumption of renters also responds to predictable house price changes, we conclude that house prices are related to borrowing constraints or precautionary savings at the aggregate rather than the household or regional level.

In our analysis we define cohorts by variables that households themselves choose, namely location and homeownership. In order to control for the endogeneity of cohort membership, one should estimate a selection equation jointly with the consumption Euler equation on the household level. Unfortunately due to the repeated crosssection nature of the data, this is not feasible. We therefore address endogeneity in several other ways. First, we use the British Household Panel Survey to calculate measures of mobility across cohorts for different age groups. This analysis tells us that first-time home purchases are the most common form of cohort transition. Second, we use the length of time that a household has resided at its present address to implement alternative cohort definitions for young homeowners. Third, we calibrate a life-cycle 
model of consumption and housing choices. We use the model to generate simulated data in which we can assess the potential bias introduced by our endogenous cohort definitions..

We also use this model to help us interpret our empirical results. Most importantly, in the FES data the estimated consumption response of young renters to house price changes is essentially zero, and not negative as one would expect from a wealth effect. Interestingly, the response is similar in the simulated data. We show that this arises from a substitution effect which counteracts the wealth effect: as house prices increase households tend to substitute non-durable consumption for housing consumption. This effect is largest in magnitude for young renters.

There is a small recent literature that uses microeconomic data to study housing. Much of this literature asks how housing affects savings and asset allocation. Engelhardt (1996), Flavin and Yamashita (2002), Goetzmann (1993), Sheiner (1995), and Skinner (1994) present empirical results, while Cocco (2005) and Yao and Zhang (2005) develop life-cycle models. Attanasio and Weber (1994), in the paper that is closest to ours, use FES micro data to investigate whether financial liberalization in the 1980s was responsible for the UK consumption boom at the end of that decade. Attanasio and Weber study the consumption patterns of different groups that are likely to be differently affected by financial liberalization, including homeowners and renters, and households living in different regions. However, they do not estimate consumption elasticities with respect to house prices for these groups. This and our model of consumption and housing choices are the main contributions of our paper.

The paper is organized as follows. Section 2 describes the data, and presents some summary statistics. This section also describes the different ways in which we construct pseudo-panels from repeated cross sections. Section 3 presents estimation results for our baseline regression, which consists of regressing changes in cohort consumption on changes in house prices, controlling for changes in cohort income, leverage, and demographic variables. In section 4 we set up and solve a life-cycle model of the consumption and housing choices of households. We use this model to help us interpret our empirical results. In section 5 we distinguish predictable and unpredictable movements in house prices and consumption, thereby partially disentangling wealth effects from other effects of house prices that work through borrowing constraints, precautionary saving, or myopic behavior. Section 6 concludes. The appendix provides additional robustness checks. 


\section{The Data}

\subsection{The Family Expenditure Survey}

We obtain household-level data from the UK Family Expenditure Survey (FES) over the period 1988 to 2000. The FES is a continuous survey of households. Each household is interviewed only once. Each quarter there are about 1,750 households interviewed, so that over the thirteen years that constitute our sample there are approximately 91,000 observations. During a two week period the adult members of each household keep a diary of their consumption expenditures. In addition the survey contains a variety of other information, including the region where the household lives, income, demographics such as age and household composition, homeownerhsip status, and mortgage information.

We define total non-durable consumption as the sum of the two week reported expenditure on fuel, travel (excluding the purchase of any vehicles), food, alcohol, tobacco, clothing, household services, leisure goods and services, and other expenditure. For each of these goods we also have monthly price indices which we use to construct a household specific Stone price index, using the household-budget shares as weights. We use this household-specific price index to obtain real non-durable consumption and income. These measures are similar to those constructed in empirical consumption studies, which will make it easier to compare our results to those previously obtained.

Most of the existing empirical tests of consumption theories focus on non-durable consumption. $^{3}$ Durable goods are long-lived and provide households with a flow of consumption services for several time periods. The FES and other comparable datasets contain information on durable goods expenditure, but not on durable goods consumption. This raises the additional difficulty of how to translate a given durables expenditure into a flow of consumption services. Because of these difficulties, and as in most of the consumption literature, we focus our analysis on non-durable consumption.

\footnotetext{
${ }^{3}$ Important exceptions are Mankiw (1982) and Heaton (1993). See also Piazzesi, Schneider and Tuzel (2003) and Yogo (2003) for recent papers testing non-separabilities between non-durable consumption and housing and durable consumption, respectively. Fernandez-Villaverde and Krueger (2005) characterize the evolution of durable expenditures over the life-cycle.
} 


\section{$2.2 \quad$ Life-cycle patterns}

In the FES each household is observed only once, so we use the methodology introduced by Browning, Deaton, and Irish (1985) and Deaton (1985) to construct panel data from a time-series of cross-sections, or a pseudo-panel. In this section we define cohorts based on the year of birth of the household head. Each cohort consists of households whose head was born within one five-year period: The oldest cohort is for individuals born between 1935 and 1939, and the youngest for individuals born between 1965 and 1969.

To obtain some insights about the evolution of the variables over the life-cycle we first regress log consumption and log income on 91 year-cohort dummies, which correspond to seven cohorts and thirteen years of data, and three quarter dummies that capture seasonal effects. Each of the estimated coefficients on the year-cohort dummies capture mean cohort-year log consumption or income. Figure 2 plots the evolution of annualized non durable consumption and income over the life cycle. Each line corresponds to a different cohort. The age profiles are hump-shaped over the lifecycle, and similar to those obtained by Attanasio and Browning (1995), Carroll (1997), and Gourinchas and Parker (2002), among others. It is important to note that Figure 2 does not control for changes in family composition or other demographic variables.

In Figure 3 we again plot annual consumption and income, but with the sample restricted to homeowners. As expected, the labor income of homeowners is on average higher. Comparing the consumption profiles in Figures 2 and 3, we can see that, for each cohort, the consumption growth of homeowners is higher than that of the population as a whole. Obviously, one needs to be careful in interpreting this finding. Homeownership is endogenous, and correlated with income growth and demographic variables that may affect the growth rate of consumption.

To illustrate homeownership patterns over the life-cycle Figure 4 plots, for the different cohorts, the proportion of renters, homeowners with a mortgage, and homeowners outright. The proportion of renters is highest early in life, but declines steadily over life to reach roughly twenty percent from age forty-five onwards. Early in life and in mid-life the vast majority of homeowners have a mortgage outstanding. Because of this one may expect that mortgage payments, and more generally the leverage of the household, affect consumption patterns.

In the UK the vast majority of mortgages are adjustable-rate. Fixed-rate mort- 
gages have become somewhat more common in the last few years, but these are not comparable to fixed-rate mortgages in the US as they have a fixed rate only for a couple of years and then revert to an adjustable rate. Figure 5 plots the life-cycle pattern of real mortgage payments for the sample of mortgage borrowers. Mortgage payments are highest early in life, and decline over the life-cycle. The decline would be even larger if we used the full sample of homeowners, as a result of the increase in the proportion of owners outright shown in Figure 4.

Real payments on adjustable-rate mortgages are highly sensitive to movements in inflation and nominal interest rates. An increase in expected inflation drives up nominal interest rates and required nominal payments, but in the short run the price level does not increase proportionally so real mortgage payments increase (Campbell and Cocco, 2003). This effect can be seen in Figure 5, where for each cohort there is a similar pattern in real mortgage payments over time, with high real mortgage payments in the early years of the survey, and low in the later years. This reflects the high nominal interest rates in the years 1989 to 1992 (illustrated in Figure 1).

To explore this issue further we have also computed, for each cohort, the correlation between real mortgage payments and the nominal interest rate: these correlations are large and positive, with an average value of 0.81 and a range from 0.71 to 0.89 . Real mortgage payments are more strongly correlated with the nominal interest rate than with the real interest rate (an average correlation of only 0.67 ). This reflects the fact that high nominal interest rates accelerate the required real payments on adjustable-rate mortgages (Campbell and Cocco, 2003).

\subsection{Regional and homeownership cohorts}

In the previous section we grouped households only by their year of birth. We now exploit other information in the dataset by defining cohorts in two alternative ways. In the first, we define nine cohorts based on the year of birth of the household head and the region where the household lives. We consider three ranges for the year of birth and three UK regions: North, Center and South. ${ }^{4}$ These regions were defined based on the correlation between house prices among them. We would like to be able

\footnotetext{
${ }^{4}$ The North includes households living in Scotland, North West, North East, Yorkshire and Humberside. Center: East Midlands, West Midlands, Wales, Eastern Anglia. South: South East, South West, London.
} 
to consider finer ranges for year of birth and region in our cohort definitions, but that would lead to a decrease in cell size and to an increase in measurement error.

Panel A of Table 1 shows the nine regional cohorts that we consider, together with the age of the head of the household in 1988 and 2000. We exclude elderly households since their consumption patterns are likely to be heavily influenced by health considerations which affect their subjective discount rate. The table also reports, for each cohort, the minimum, maximum, and mean quarterly cell size. The fact that we have regional consumption and house price data will allow us to investigate whether regional house prices explain regional consumption patterns, beyond what is explained by UK wide house prices. ${ }^{5}$

We construct a second set of cohorts based on the year of birth of the household head and homeownership status. More precisely, we consider six ranges for the year of birth, and whether the household is a renter or homeowner. Being able to distinguish between homeowners and renters is important for understanding the link between house prices and consumption for several reasons. First, renters are short in housing and therefore the wealth effect associated with a house price increase should be negative. Second an increase in house prices does not directly lead to a relaxation of the borrowing constraints renters face. Thus, unless the house price increase is due to improved future aggregate economic conditions, which also benefit renters, an increase in house prices should have a negative effect on the consumption of renters.

Panel B of Table 1 reports for each cohort of homeowners and renters the minimum, maximum and mean cell size. Mean cell size is relatively small for old renters. Due to cell size considerations, when we construct cohorts based on homeownership status we cannot split cohorts further based on the region where the household lives. This means that we lose explanatory power from regional differences, unless different cohorts of homeowners and renters tend to live in different regions. Another important issue that one needs to keep in mind when interpreting the regression results for these cohorts is that homeowners and renters differ along several important dimensions. Homeowners are on average older than renters (median age of 40 as compared with 36 for renters), have larger families (mean family size of 3 as compared with 2.8 for renters), $104 \%$ greater income, and 33\% greater consumption than renters.

Table 2 reports some summary statistics for our cohort mean data, including con-

\footnotetext{
${ }^{5}$ Lustig and Van Nieuwerburgh (2004) use US regional data to test the extent to which borrowing against housing allows for consumption risk sharing across regions.
} 
sumption, income, and family size. The cohort mean is defined as the average of the logs. Panel A reports the data for the regional cohorts, whereas Panel B reports the data for the cohorts of homeowners and renters. The sample selection issue that arises from our split of the sample between homeowners and renters can clearly be seen in Panel B, in the quarterly differences in income and consumption. As they age, those households that remain renters are those with lower income and consumption. In section 4 we explore several alternative ways to handle this endogeneity of homeownership.

\subsection{House price data}

We obtain house price data from Nationwide, a leading UK building society. Nationwide house prices are mix adjusted, i.e. they track a representative house price over time, rather than the simple average price. This avoids the house price index being influenced by a change in the mix of houses (proportion of different property types, locations, etc). Nationwide obtains the house price information from their lending data for properties at the post survey approval stage. Importantly, this introduces some lag in the house price data, since the transaction price will probably have been agreed between buyer and seller a few weeks before this date. ${ }^{6}$

We match the quarterly regional house price indices from Nationwide to each household in the FES. In this way we are able to obtain, for each household, a region specific measure of house prices, which should allow us to obtain a better estimate of the effect of house prices on consumption, than simply using a UK wide house price index.

Table 3 reports the coefficients of correlation between quarterly (and annual) house price changes in the three regions we define. As expected the correlations are higher between regions that are closer geographically (North and Center, and Center and South), and are somewhat higher for annual than quarterly house price changes. Figure 6 plots the evolution over time of house prices in these three regions.

In addition to this information, we obtain quarterly series for nominal interest rates, namely the Bank of England rate, and the retail price index. We show the

\footnotetext{
${ }^{6}$ More information on the methodology used by Nationwide to construct the house price series is available at http://www.nationwide.co.uk/hpi/methodology.htm. The house price data are available at http://www.nationwide.co.uk/hpi/historical.htm.
} 
history of nominal interest rates and inflation together with house price returns in Figure 1.

\section{House Price Changes and Consumption}

\subsection{Baseline regression}

We first present our baseline regression, which consists of regressing changes in consumption on changes in house prices, controlling for household income, leverage, and other demographic variables. We estimate this regression using a pseudo-panel constructed in several different ways, that explore the micro nature of the data, and allows us to partially disentangle between the different channels through which house prices may affect consumption. More precisely, we estimate:

$$
\Delta c_{i, t+1}=\beta_{0}+\beta_{1} r_{t+1}+\beta_{2} \Delta y_{i, t+1}+\beta_{3} \Delta p_{i, t+1}+\beta_{4} \Delta m_{i, t+1}+\beta_{5} Z_{i, t+1}+\epsilon_{i, t+1}
$$

where the subscript $i$ denotes cohort, $r_{t+1}$ is the log real interest rate between periods $t$ and $t+1, \Delta c_{i, t+1}=\ln \left(C_{i, t+1}\right)-\ln \left(C_{i t}\right)$ is real non-durable consumption growth, $\Delta y_{i, t+1}=\ln \left(Y_{i, t+1}\right)-\ln \left(Y_{i t}\right)$ is real income growth, $\Delta p_{i, t+1}=\ln \left(P_{i, t+1}\right)-\ln \left(P_{i t}\right)$ is real house price growth, $\Delta m_{i, t+1}=\ln \left(M_{i, t+1}\right)-\ln \left(M_{i t}\right)$ is the growth of real mortgage payments, and $Z_{i, t+1}$ is a vector of cohort characteristics which includes demographic variables.

\subsection{Results for regional cohorts}

Table 4 shows the estimation results for the baseline regression (1), for several different specifications. The standard errors reported in parentheses below the estimated coefficients are corrected for both first-order serial correlation and heteroscedasticity. In all specifications we include quarter and cohort dummies (the estimated coefficients are not reported), and we control for demographics by including a second order polynomial of age and changes in the logarithm of family size. 
In specifications (i) and (ii) we include as independent variables changes in log household income and house prices in the region where the household lives, respectively, whereas in specification (iii) we include these two variables simultaneously. The estimated coefficients are positive and statistically significant, so that consumption growth is positively correlated with income growth and house price changes. The estimated coefficients on house prices and income decrease in magnitude when we include these two variables simultaneously in the regression, which suggests some degree of collinearity between regional house prices and income. Nevertheless, both are significant in statistical and economic terms in specification (iii).

The estimated coefficient on house prices in this specification is 1.22 . Thus, a one percent increase in the value of the house is associated with a 1.22 percent increase in real non-durable consumption. To understand what such a value means in British pounds, let us consider the value of a representative house in the UK in the last quarter of 2000 , which was $£ 81,628$. In the same year the average consumption from the FES data was $£ 200$ per two-week period or $£ 5200$ per year. Thus, an increase in the value of the house by one percent or $£ 816$ would lead to an increase in annual consumption of $£ 63$, equivalent to $8 \%$ of the house price increase.

In specification (iv) we also include as independent variables the change in the proportion of homeowners, both with a mortgage and outright. The estimated negative coefficients show that increases in the proportion of homeowners are associated with slower non-durable consumption growth. However, neither of the estimated coefficients is significantly different from zero.

The regional cohorts definition allows us to investigate whether regional house prices explain regional consumption, beyond what is explained by UK wide house prices. We switch from regional to national house prices in specification (v), and add both national house prices and the difference between regional and national house prices in specification (vi). The difference between regional and national house prices is statistically significant, confirming the existence of a regional link between house prices and consumption.

Given the prevalence of adjustable-rate mortgages in the UK, changes in mortgage payments may be an important influence on consumption and may be correlated with house prices. To explore this effect specification (vii) includes changes in real mortgage payments as an additional explanatory variable. The estimated coefficient is not significantly different from zero and the inclusion of mortgage payments has little effect on the house price coefficients. We have also tested whether a given 
percentage house price increase has a bigger proportional effect on consumption if households are highly leveraged, by interacting house price growth with the level of the mortgage-income ratio. When we include this variable in the regression the estimated coefficient is positive but not significantly different from zero. To save space we do not report this specification in the table.

The apparent effect of regional house prices on consumption could result from changes in regional economic conditions that move both house prices and consumption. In order to investigate this possibility we follow Gourinchas and Parker (2002) and use the unemployment rate to capture the state of the business cycle. Regional unemployment data are available in the UK only from the second quarter of 1992, but the regional claimants count rate is highly correlated with regional unemployment and is available from 1965; therefore we use the latter data series to proxy for regional business cycle conditions. ${ }^{7}$ Column (viii) of Table 4 shows regression results when we include the change in the regional claimant count rate as an additional independent variable. The estimated coefficient on this new variable is negative, as we would expect, but not significant, while the estimated coefficient on house price changes changes only slightly. These results suggest that house prices have an independent effect on consumption and are not merely proxying for the regional business cycle.

Due to the cohort nature of the data the estimation results shown in columns (i) through (viii) of Table 4 are subject to potential problems of measurement error and endogeneity in the regressors. This problem is likely to be more serious for income than for house prices, since the latter are measured using house price indices from Nationwide rather than cohort averages. In order to address this issue, in the last two columns of Table 4 we estimate instrumental variable regressions, where we instrument income and house price changes using changes in the regional claimants count rate, house price changes, and the second lag of changes in income.

Comparing the results in columns (iii) and (ix), we see that when we instrument income, the estimated coefficient on income changes is slightly increased, and the estimated coefficient on house prices decreases by roughly a half but is still positive and significantly different from zero. In column (x) we include as independent variables the change in UK wide house prices, and the difference between the change in regional house prices and the change in UK wide house prices. We include both of these variables in our set of instruments. Comparing columns (vi) and (x) we see that

\footnotetext{
${ }^{7}$ The correlation of the regional claimants count rate with regional unemployment over the period where both series are available is 0.99 in the North and South, and 0.98 in the Center.
} 
as before the estimated coefficients on house price changes decrease, but the effect of UK house prices on consumption is still positive and significant. The estimated coefficient on the difference between regional and UK wide house price changes is now insignificant, with a p-value of $18 \%$.

\subsection{Results for homeownership cohorts}

Table 5 estimates the baseline regression for cohorts of homeowners and renters. As before we find that house price changes are positively correlated with consumption growth, and that this correlation decreases when we control for labor income growth. The sensitivity of consumption to house prices may depend on age and homeownership status. To explore these effects, in specification (iv) we interact house price changes with dummy variables for young homeowners, young renters, and old renters. ${ }^{8}$ In this specification the estimated coefficient on $\Delta p_{t}$ measures the effects of house price changes on the consumption of old homeowners, and the estimated coefficients on the interaction variables measure the additional effects of house prices for the particular groups defined by the dummy variables.

We find significant heterogeneity in the consumption effects of house prices across the different groups. The estimated coefficient on house prices is highest for old homeowners, and is almost three times the coefficient we estimated in specification (iii) where we did not interact house price changes with age and homeownership status. The effects of house prices on consumption are lower for young homeowners and for renters than for old homeowners, since we estimate negative coefficients for house price changes interacted with dummy variables for these groups. In fact, the magnitude of the estimated coefficients tells us that the effects of house price changes on consumption are lowest for young renters, followed by old renters and young homeowners. All these estimated coefficients are statistically different from one another at the $1 \%$ significance level, except that the estimated coefficients for young homeowners and old renters are insignificantly different from one another. The effect of house prices on consumption is not statistically different from zero for young renters, but it is significantly positive for all other groups of individuals. The fact that the estimated coefficient on house prices for old renters is positive suggests that house prices may, to some extent, proxy for aggregate economic conditions.

\footnotetext{
${ }^{8}$ We set the boundary between youth and old age at 40 . To soothe the feelings of the senior author, we experimented with a boundary of 45 and obtained similar results.
} 
In specifications (v) and (vi) we include changes in real mortgage payments as an additional explanatory variable. In specification (v) we include it on its own, and in specification (vi) we include it on its own and also interacted with a dummy variable for young homeowners. Obviously, for renters these variables are equal to zero. Interestingly, we find that increases in real mortgage payments are negatively correlated with consumption growth (specification v), and that this negative effect is due to the changes in real mortgage payments of young and not old homeowners (specification vi). Since in the UK the vast majority of mortgages are adjustable-rate, and mortgage payment changes have no wealth effects for these mortgages (Campbell and Cocco 2003), the likely explanation for the negative estimated coefficient is the presence of borrowing constraints. ${ }^{9}$

In order to address the issue of measurement error in income, the last column of Table 5 reports the estimation results for an instrumental variables regression. We instrument changes in income and in house prices, also interacted with the dummy variables for age and homeownership status, with changes in unemployment, changes in house prices, also interacted with the dummy variables, and changes in the second lag of income. Comparing the estimation results in column (vii) to those in column (iv) we see that the estimated coefficients on house price changes decrease somewhat, but they remain statistically significant. It is still the case that the effects of house price changes on consumption are largest and positive for old homeowners, and are smallest and close to zero for young renters.

The small effect of house prices on the consumption of young renters is puzzling since a wealth effect should lead these households to cut consumption when house prices increase. In the next section we use a calibrated life-cycle model of consumption and housing choices to help us understand this finding.

\footnotetext{
${ }^{9}$ To further investigate this issue we have looked at the effect of inflation on consumption. Inflation affects the payments required on adjustable-rate mortgages, and avoids the problem that mortgage payments vary if households take out bigger mortgages. However, when we include inflation as an additional independent variable its estimated coefficient is not significantly different from zero. To save space we do not report this result in the table.
} 


\section{Selection Bias and a Simulated Housing Model}

We have divided the sample between homeowners and renters and have treated homeownership status as an exogenous variable. This is problematic, because the decision to become a homeowner is endogenous, and correlated with individual characteristics such as income and consumption. Over the life-cycle, individuals who remain as renters typically have stagnating or declining incomes, while individuals with rising incomes tend to become homeowners. It follows that over time for a fixed birth year, the cohort of renters shrinks and becomes more concentrated in the low-income population. This effect is clearly visible in Table 2, panel B, which shows that average consumption and income growth are negative for renters and positive for homeowners. Thus, the endogeneity of homeownership clearly affects the cohort means of consumption and income within our pseudo-panel. Fortunately these average cohort effects are captured by the fixed effects in our regressions.

More problematic for our analysis is if there is also an effect on covariances and thus on the estimated regression coefficients. For example, suppose that house price movements affect renters' decisions to buy their first homes. In this case, for a fixed birth year, the mean consumption of renters in quarter $t$ may be higher or lower than in quarter $t-1$ simply because more or fewer renters with higher consumption and income became homeowners. Even though in the regressions we are controlling for the income of the same individuals, there may be some correlation between changes in house prices and consumption that is simply due to renters becoming homeowners. This may bias our estimation results.

The ideal solution to this problem is to estimate a selection equation jointly with the consumption Euler equation on the household level. Unfortunately due to the repeated cross-section nature of the data, this is not feasible. We have investigated if there are techniques that deal with this sample selection issue in a synthetic cohort framework, but without success. In addition, all micro datasets that contain reasonably good consumption data are repeated cross sections.

As a first step to understand the magnitude of the potential bias arising from cohort selection, we have calculated measures of regional mobility and housing tenure by age using the British Household Panel Survey (BHPS). Unlike the FES, the BHPS is a panel so that each household is tracked over time. However the BHPS contains no detailed consumption information. The BHPS data are annual and start in 1991. We use data from 1991 through 1999, corresponding roughly to our FES sample period. 
We define the same three regions as we did for the FES, and calculate the frequency with which households of a given age change their region of residence from one year to the next. Table A.1 in the Appendix reports these transition probabilities by age. For the vast majority of age groups and regions, the probability that a household moves from one region to another is less than one percent. The main exception is that the youngest group (age 20-24) has a 3\% probability of moving from the North to the Center, and a $1 \%$ probability of moving from the North to the South. These numbers suggest that any bias arising from regional endogeneity is small.

We have also used the BHPS to calculate transition probabilities from renting to homeownership and vice versa, by age. Table A.2 in the Appendix reports the results. Young households move from rental to owner-occupied housing quite frequently; the transition probabilities start at $12 \%$ for age $20-24$ and decline smoothly to $9 \%$ for age $30-34$ and $6 \%$ for age 40-44, flattening out in middle age and then declining again to around $2 \%$ for households in their 60 's. Young households also transition from homeownership to renting, with a $6 \%$ probability for age 20-24, but this transition probability declines rapidly and is $1 \%$ or below for households aged between 40 and 80. These numbers suggest that younger homeowners include some households that have just switched from renting, and this may affect our regression results for younger households.

In the Appendix we try variations of our basic method that restrict the sample to households that have lived for longer than six months at their present address, or that treat young homeowners that have recently moved as if they were still renters. The results, reported in Tables A.3 and A.4, are generally comparable to those reported in the body of the paper.

\subsection{A model of housing choice}

Another approach to the cohort selection problem is to use a calibrated model of consumption and housing choice in which we can evaluate the magnitude of the effects caused by cohort selection. We now set up and solve such a model. We augment the life-cycle framework of Deaton (1991), Carroll (1997), and Gourinchas and Parker (2002), which allows for borrowing constraints and labor income uncertainty, to include housing choices, namely the decision to own or rent a house and the size of house to occupy. The model allows for house price uncertainty and is related to recent work of Cocco (2005) and Yao and Zhang (2005). 
Time parameters and preferences

We model the consumption and asset choices of a household, indexed by $i$, who lives for a maximum of $T$ periods. We allow for uncertain life span in the manner of Hubbard, Skinner and Zeldes (1994). Let $s_{t}$ denote the probability that the household is alive at date $t+1$, conditional on being alive at date $t$.

In each period $t$, the household needs to choose whether to rent or own a house and its size, $H_{i t}$, and other non-durable goods consumption, $C_{i t}$. The date $t$ price per unit of housing is denoted by $P_{t}$, such that a house of size $\bar{H}$ has price $P_{t} \bar{H}$ at date $t$. The size of the house should be interpreted broadly as reflecting not only the physical size, but also its quality. The price of other goods consumption (the numeraire) is fixed and normalized to one. We assume that a house sale is associated with a transaction cost $\lambda$, which is a proportion of house value.

The household derives utility from both housing and non-durable goods, and after death from bequeathing terminal wealth. We assume that preferences are time additive, and that they are separable between housing and non-durable goods consumption, such that per period utility is given by:

$$
u\left(C_{i t}, H_{i t}\right)=\frac{C_{i t}^{1-\gamma}}{1-\gamma}+\theta \frac{H_{i t}^{1-\gamma}}{1-\gamma}
$$

where $\gamma$ is the coefficient of relative risk aversion, and $\theta$ measures preference for housing relative to non-durable consumption goods. The utility derived from bequeathing terminal wealth is given by:

$$
v\left(W_{i t}\right)=b \frac{W_{i t}^{1-\gamma}}{1-\gamma}
$$

where $b$ measures the intensity of the bequest motive, and $W_{i t}$ is the amount of wealth the household bequeaths its descendants at death. This includes both housing and non-housing wealth. It is important to note that our preference specification allows for a precautionary savings motive. We let $\beta$ denote the time discount factor. 


\section{Labor income risk}

The household works for the first $K$ periods of its life. In each of these periods it is endowed with stochastic labor income, $Y_{i t}$, which cannot be traded or used as collateral for a loan. As usual we let a lower case letter denote the natural log of the variable, so $y_{i t} \equiv \log \left(Y_{i t}\right)$. Household $i$ 's log real labor income during working life is exogenous and is given by:

$$
y_{i t}=f\left(t, Z_{i t}\right)+v_{i t}+\omega_{i t} \quad t<K
$$

where $f\left(t, Z_{i t}\right)$ is a deterministic function of age $t$ and other individual characteristics $Z_{i t}$, and $v_{i t}$ and $\omega_{i t}$ are stochastic components of income. Thus log income is the sum of a deterministic component that can be calibrated to capture the hump shape of earnings over the life-cycle, and two random components, one transitory and one persistent. The transitory component is captured by the shock $\omega_{i t}$, an i.i.d. normally distributed random variable with mean zero and variance $\sigma_{\omega}^{2}$. The persistent component is assumed to be entirely permanent; it is captured by the process $v_{i t}$, which is assumed to follow a random walk:

$$
v_{i t}=v_{i, t-1}+\eta_{i t}
$$

where $\eta_{i t}$ is an i.i.d. normally distributed random variable with mean zero and vari-

ance $\sigma_{\eta}^{2}$. Income during retirement is assumed to be a proportion $r$ of permanent income at retirement age such that:

$$
y_{i t}=r\left(f\left(K, Z_{i K}\right)+v_{i K}\right) \quad t \geq K
$$

Our assumptions about the labor income process are similar to those made by Carroll (1997) and Gourinchas and Parker (2002).

\section{House prices}

The price of housing fluctuates over time. Let $P_{i t}$ denote the date $t$ real price of one unit of housing in the region where household $i$ lives. Real house price growth is given by: 


$$
\Delta p_{i t}=g+\delta_{i t},
$$

a constant $g$ plus an i.i.d. normally distributed shock $\delta_{i t}$ with mean zero and variance $\sigma_{\delta}^{2}$. To economize on state variables we assume that innovations to house prices are perfectly positively correlated with innovations to the permanent component of the household's labor income so that

$$
\delta_{i t}=\alpha \eta_{i t},
$$

where $\alpha>0$. This assumption implies that states with low house prices are also states with low permanent labor income. ${ }^{10}$

\section{Financial assets and borrowing}

There is a single financial asset with riskfree interest rate $R$, in which households may invest. Homeowners may also borrow at this rate, up to the current value of the house minus a downpayment. If we let $D_{i t}$ denote date $t$ outstanding debt, the borrowing constraint faced by homeowners is given by

$$
D_{i t} \leq(1-d) P_{i t} H_{i t},
$$

where $d$ is the downpayment. We allow homeowners to borrow against the value of their house at the riskfree rate. Because of this we also rule out default. We do so by imposing the following additional constraint:

$$
D_{i t}(1+R) \leq(1-\lambda) \underline{P_{i, t+1}} H_{i t}+\underline{Y_{i, t+1}},
$$

where $\lambda$ is the transaction cost associated with a house sale, $P_{i, t+1}$ and $Y_{i, t+1}$ are

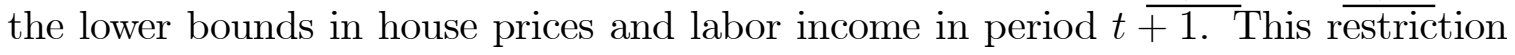
guarantees that the household is always able to repay the loan.

\footnotetext{
${ }^{10} \mathrm{~A}$ large positive correlation between income shocks and house prices is also present in OrtaloMagné and Rady (2001).
} 
Rental cost and probability of a forced move

We set the rental cost equal to the user cost of housing plus a constant rental premium, $\theta^{R}$. Thus the rental cost is equal to fraction $\left(R-g+\theta^{R}\right)$ of the house value. The rental premium covers the moral hazard problem of renting, that tenants have no incentive to look after a property so that maintenance becomes more expensive.

We assume that in each period and with probability $\pi$ the household is forced to move. In this case homeowners incur the transaction cost associated with the house sale.

Summary of the household's optimization problem

In summary, the household's control variables are $\left\{C_{i t}, S_{i t}, H_{i t}\right\}_{t=1}^{T}$, where $S_{i t}$ takes the value of if the household decides to own a house, and zero otherwise. The vector of state variables is $X_{i t}=\left\{t, p_{i t}, W_{i t}, S_{i, t-1}, H_{i t}, M_{i t}\right\}_{t=1}^{T}$, where $W_{i t}$ is real liquid wealth or cash-on-hand and $M_{i t}$ is a state variable that takes the value of one in periods the household is forced to move and zero otherwise.

The equation describing the evolution of real cash-on-hand for homeowners in a period in which the homeowner does not move houses:

$$
W_{i, t+1}=\left(W_{i t}+Y_{i t}-C_{i t}\right)(1+R)
$$

or in a period when the homeowner sells his house to buy another one:

$$
W_{i, t+1}=\left(W_{i t}+Y_{i t}-C_{i t}-P_{i t} H_{i t}+(1-\lambda) P_{i t} H_{i, t-1}\right)(1+R)
$$

where $\lambda$ is the proportional transaction cost of selling a house. 


\subsection{Parameterization of the model}

Adult age in our model starts at age 20 and we let $T$ be equal to 100 years. For computational tractability, we let each period in our model correspond to five years but we report annualized parameters and data moments for ease of interpretation. To parameterize survival probabilities, we use data from the interim life tables for UK males produced by the UK Government actuary's department.

We use data from the Family Expenditure Survey to estimate the labor income profile. More precisely, we regress the natural logarithm of household income on age dummies, quarter dummies, family composition, and cohort dummies. We then fit a third order polynomial in age to the estimated age dummies, and compute five-year labor income by adding estimated labor income over the relevant age group. The cohort approach to estimating labor income profiles yields a fairly large standard deviation of residuals, as high as $60 \%$ in our implementation. Obviously, this is the result of measurement error, and cannot be interpreted as a measure of the income risk faced by households. For this reason we use lower values for the variance of income shocks, in line with those used by Deaton (1991) and Carroll (1997). These values are reported in Table 6.

In order to parameterize the house price process we look at Nationwide house price data for all UK houses from 1953 to 1999. The mean real house price growth over this long period was $2.1 \%$, with a standard deviation of $6.2 \%$. Part of the appreciation in house prices reflects improvements in the quality of housing. For this reason we use a lower value of $1 \%$ for average real house price growth.

Other parameters of the model are reported in Table 6. We assume that households have risk aversion of 3 and a discount factor of 0.98 . The real interest rate and the rental premium are both set to $1 \%$, the exogenous moving probability is $5 \%$, and the transactions cost of selling a house is $8 \%$. Purchasing a house requires a downpayment of $15 \%$ of house value.

We use the model to generate simulated data. For the baseline parameterization, all households become homeowners in middle age. In order to better match the data, we therefore assume that the population is heterogeneous with respect to the discount factor. More precisely, we assume that $70 \%$ of households are described by the baseline parameters shown in Table 6 , and the remaining $30 \%$ are more impatient, with a time discount factor of 0.85 . Impatient households tend to rent housing 
throughout their lives, since they do not wish to accumulate the savings needed to make a downpayment on a house.

We also consider another type of heterogeneity, namely in the probability of a forced move. In this case $70 \%$ of households are described by the baseline parameters shown in Table 6, and the remaining $30 \%$ have a $10 \%$ annual probability of a forced move. These households tend to rent housing throughout their lives to avoid the large transactions costs of forced moves for homeowners. Obviously, it would be possible to allow other types of heterogeneity, but these two seem to be realistic and interesting while keeping the model relatively simple.

Table 7 reports summary statistics from the simulated data and compares them to the BHPS data for several different age groups. The model is fairly successful in matching homeownership rates in mid- and late life, but is less successful in early life. The reason is that in the simulated data households seem to take longer than in the BHPS data to accumulate the downpayment needed to become homeowners. One possible explanation for this is that some households receive inter-vivos transfers from their parents to help them buy their first houses. Table 7 also shows the average annual moving probabilities in the BHPS and simulated data. The largest differences are in the moving probability for young homeowners. Households in the model take longer to become homeowners, and are less likely to move early in life. In addition, middle-aged and older renters are more likely to move in the model than in the BHPS data. We could match the data better by assuming an age-varying probability of a forced move, or an age-varying preference for housing relative to nondurable consumption. However this would complicate the model and we proceed with the relatively simple specifications of Table 7 .

\subsection{Model results: addressing selection bias}

In Table 8 we estimate regressions on the simulated data similar to those that we have previously estimated using FES data. All regressions include a second order polynomial in age, but to save space we do not report these coefficients. Basic results are given in column (i) for a population with heterogeneous discount factors, and column (iv) for a population heterogeneous in moving probability. Just as in the FES data, house prices have the largest effects on non-durable consumption for old homeowners, and smaller effects for renters. Contrary to the FES data, however, we find that the effect of house prices on consumption is lowest for old and not young 
renters. Columns (ii) and (v) help us understand why.

In these columns we allow the estimated coefficient on income changes to vary with homeownership status and age, similarly to the effects of house prices. In this case we do find that the effects of house price changes on consumption are largest for old homeowners and smallest for young renters. In addition, we find that the effects of income changes on consumption are largest for young renters. This higher sensitivity of consumption to income changes is due to the fact that young renters are the ones who are most borrowing constrained. When we do not allow the effects of income changes to vary by age and homeownership status, the estimated coefficient on $\Delta y_{t}$ estimates an average effect across the different groups. Since house prices are correlated with income growth, the regression compensates for its inability to increase the income coefficient for young renters by increasing the house price coefficient for young renters.

We note that in column (ii) old renters have a higher sensitivity to income changes than old homeowners, but this is not true in column $(\mathrm{v})$. The reason is that in the data used to estimate (ii), old renters have lower discount rates and tend to be borrowing constrained, whereas in the data used to estimate $(\mathrm{v})$, old renters are households that face a higher moving probability but are not necessarily borrowing constrained.

The regressions in columns (ii) and (v) do not control for the fact that the decision to become a homeowner is endogenous. That is, we have exogenously specified cohorts along the housing tenure dimension. This may bias the estimated coefficients. In order to examine the extent to which that is the case, in columns (iii) and (vi) we estimate two equations jointly. In the first equation, whose estimation results are shown in Panel A, the dependent variable is a dummy variable that takes the value of one when there is a transition from renter to homeowner. The independent variables are income, financial savings, and house price changes. The second equation, whose estimation results are shown in Panel B, is similar to the one previously estimated, with consumption growth as the dependent variable. These equations are jointly estimated by maximum likelihood.

The estimation results shown in Panel A indicate that households with higher income are more likely to become homeowners. Financial savings also predict homeownership if the population is heterogeneous in the discount factor. Finally, renters are less likely to become homeowners in periods of rising house prices.

Panel B reports the coefficients for the consumption growth equation. As before, 
we estimate a positive house price coefficient for old homeowners, and the house price coefficient is smallest for young renters. The main difference relative to columns (ii) and $(\mathrm{v})$ is that rising house prices are now estimated to have the largest effect on the consumption of young homeowners rather than old homeowners. The strong effect for young homeowners in columns (iii) and (vi) is presumably due to the fact that these households tend to be borrowing constrained, and rising house prices relax their constraints. The effect is estimated to be smaller in columns (ii) and (iv) because low-income households tend to buy houses and join the group of homeowners when house prices decrease, biasing the house price coefficient downward in the models that do not account for cohort selection.

In the simulated data, the total effect of house price changes on consumption for young renters is close to zero, but is not negative as one would expect from a wealth effect. This is also the case in the FES data, as reported in Table 5. We can use our model to understand why young renters do not increase their savings when house prices increase. In Appendix Table A.5 we use simulated data to estimate the effects of income and house prices on the decision to buy a house and the size of the house that is purchased. As house prices increase, renters choose to buy smaller houses. That is, they substitute nondurable consumption for housing consumption because housing services are more expensive. This substitution effect offsets the wealth effect for young renters. Obviously the magnitude of the substitution effect relative to the wealth effect depends on the degree of substitutability between housing and non-durable consumption.

While our model helps us to assess the nature of the selection bias in our empirical analysis, and to interpret our empirical results, it has an important limitation. There is no measurement error in the simulated data comparable to the measurement error that we believe to exist in the FES data. We could generate simulated data that is subject to measurement error, but this would require arbitrary decisions about the nature of the error and its cross-sectional variation across groups of households.

Measurement error in income may explain one discrepancy between our simulated data and the FES data. Table 8 shows that it is important to allow the coefficient on income changes to vary by age and with homeownership status. With this in mind we have estimated a regression on FES cohort data allowing for such variation. This regression is reported in column (vii) of Table 8. We control for age and family size, but we do not report the estimated coefficients on these variables. In the FES data we find that income changes have a larger effect on the consumption of old homeowners, 
contrary to the intuitive result in the simulated data. One possible explanation is that in the FES data the income of young renters is subject to more measurement error than that of old homeowners, biasing the estimated coefficient downwards for young renters. Fortunately this sort of measurement error cannot overturn our conclusion that the estimated response of consumption to house price changes is smallest for young renters. If the income of young renters is subject to more measurement error, and if their income is positively correlated with house prices, then measurement error is likely to bias the estimated coefficent on house price changes upwards for young renters. That is to say, the true effect of house prices on the consumption of young renters may be smaller than that estimated in column (vii) of Table 8.

\section{$5 \quad$ Predictable versus Unpredictable Changes in House Prices}

We have estimated the effects of house price changes on consumption changes using FES data. These effects may be driven by a variety of mechanisms, including wealth and substitution effects, borrowing constraints, precautionary savings, or even myopic behavior by households. In order to gain a better understanding of these mechanisms, we now distinguish between predictable and unpredictable changes in house prices. If households are forward-looking, then the wealth effect of a house price change occurs when the change can be anticipated, not when it actually occurs. On the other hand, a predictable change in house prices - one that has already been anticipated - may still relax borrowing constraints even if it has no wealth effect. Obviously, this reasoning requires that there are predictable changes in house prices, and indeed several papers have documented positive serial correlation in the returns on residential real estate (Case and Shiller 1989, Poterba 1991). It also requires that housing becomes available as collateral only when an increase in house prices is realized and not when it can be predicted. Finally it requires that borrowing capacity depends on the current, and not on the purchase price of the house.

The distinction between predictable and unpredictable house price changes does not allow us to cleanly separate the effects of borrowing constraints from wealth effects. These two effects are not mutually exclusive: an unexpected increase in house prices may have a positive wealth effect and at the same time relax borrowing constraints. Also, precautionary savings or myopic behavior may lead consump- 
tion to respond to predictable house price changes even in the absence of borrowing constraints. A theoretical model would allow us to say more, but in the model of the previous section we assumed for tractability that house prices follow a random walk. Therefore we cannot use that model to assess the effects of predictable and unpredictable changes in house prices.

\subsection{Predictable changes in house prices}

If a predictable increase in house prices relaxes borrowing constraints, the consumption of borrowing-constrained households should respond to predictable changes in house prices. Likewise, if a fraction of the households within a cohort exhibit precautionary savings or myopic behavior, then consumption will respond to predictable changes in house prices. We focus on predictable changes because there should be no wealth effect associated with them.

Our test of whether non-durable consumption responds to predictable changes in house prices is closely related to the literature on the excess sensitivity of consumption to income. The hypothesis to be tested is the permanent income hypothesis, which postulates that consumption should respond only to unpredictable changes in income. Instead, Flavin (1981) found that aggregate consumption responds positively to predictable changes in income, and interpreted this finding as evidence that consumers face borrowing constraints. Following Flavin's influential paper, there have been many papers investigating excess sensitivity and its link to borrowing constraints, precautionary savings and myopic behavior, using both macro (Hall 1978, Campbell and Mankiw 1989, 1991, Carroll and Summers 1991, Christiano, Eichenbaum, and Marshall 1991) and micro data (Hall and Mishkin 1982, Zeldes 1989, Runkle 1991, Attanasio and Browning 1995, Attanasio and Weber 1995). ${ }^{11}$

The equation that we estimate is the one usually estimated in the excess sensitivity literature. The novelty of our analysis is that we also include as a regressor house price growth in the region where the household lives. More precisely we estimate equation (1) using lagged variables as instruments, which corresponds to estimating the following model:

\footnotetext{
${ }^{11}$ See the survey of Browning and Lusardi (1996) for further references.
} 


$$
\Delta c_{i, t+1}=\beta_{0}+\beta_{1} E_{t} r_{t+1}+\beta_{2} E_{t} \Delta y_{i, t+1}+\beta_{3} E_{t} \Delta p_{i, t+1}+\beta_{4} E_{t} Z_{i, t+1}+\epsilon_{i, t+1}
$$

In words, we ask whether consumption responds to predictable changes in income and house prices. If the permanent income hypothesis were true, $\beta_{2}$ and $\beta_{3}$ should be zero. If on the other hand a fraction of the households within a cohort are borrowing constrained and a predictable increase in house prices increases their borrowing capacity, or if a fraction of the households within a cohort exhibit precautionary savings or myopic behavior, the estimated coefficient $\beta_{3}$ will be positive.

The fact that we take first differences of cohort means introduces an $M A(1)$ structure in the residuals of the equation to be estimated, which raises some important issues for our choice of instruments, and also for the computation of standard errors (see Deaton (1992) for a textbook treatment). To allow for the MA structure of the residuals we use instruments dated $t-1$ and earlier, i.e. variables twice lagged. We estimate equation (13) for all cohorts simultaneously, but include as independent variables cohort fixed effects.

In the vector of variables $Z_{i t+1}$ we include the first differences of age, age squared, and family size. These variables can be expected to appear in the felicity function so we include their change contemporaneously with the change in consumption. Age and age squared are taken as exogenous, as are the cohort and seasonal (quarter) fixed effects. However changes in family size are considered to be endogenous, so we use as an instrument the second lag of change in family size.

The real interest rate, $\Delta y_{i, t+1}$ and $\Delta p_{i, t+1}$ are also considered to be endogenous and are instrumented. We use as instruments the second lag of changes in log consumption, income, house prices, and the second lag of the interest rate and the inflation rate.

\subsection{Unpredictable changes in house prices}

If a fraction of households within the cohort are forward-looking and unconstrained, then their consumption should respond to unpredictable movements in house prices. To explore this effect, we must first identify unpredictable house price changes. We first estimate $E_{t} \Delta p_{i, t+1}$, and then obtain shocks to house prices as $\Delta p_{i, t+1}-E_{t} \Delta p_{i, t+1}$. 
In our estimate of expected house price changes, we include as explanatory variables the same instrumental variables that we used in the previous subsection.

We repeat this procedure for income, and for consumption, so as obtain measures of the unexpected changes in income and consumption, $\left(\Delta y_{i, t+1}-E_{t} \Delta y_{i, t+1}\right)$ and $\left(\Delta c_{i, t+1}-E_{t} \Delta c_{i, t+1}\right)$, respectively. We then test whether unexpected changes in consumption react to unexpected changes in house prices by estimating the following regression:

$$
\begin{aligned}
\Delta c_{i, t+1}-E_{t} \Delta c_{i, t+1}= & \alpha_{0}+\alpha_{1}\left(\Delta r_{i, t+1}-E_{t} \Delta r_{i, t+1}\right)+\alpha_{2}\left(\Delta y_{i, t+1}-E_{t} \Delta y_{i, t+1}\right) \\
& +\alpha_{3}\left(\Delta p_{i, t+1}-E_{t} \Delta p_{i, t+1}\right)+\eta_{i, t+1}
\end{aligned}
$$

where $\eta_{i, t+1}$ is the residual. It is important to clarify a few issues regarding equation (14), since this is not an equation usually estimated in the consumption literature.

If we exclude the unexpected change in house prices from the set of explanatory variables, the above equation is not very informative when trying to distinguish between different consumption theories; whether the permanent hypothesis holds, a fraction of consumers are liquidity constrained, or their behavior exhibits precautionary savings or some degree of myopia, consumption should respond positively to unexpected changes in income. The same is not true, however, for the response of consumption to an unexpected change in house prices. The sign of the estimated coefficient $\alpha_{3}$ allows us to test whether there are wealth and substitution effects associated with house price shocks. If the wealth effect dominates the substitution effect, the coefficient should be positive for households who are long in housing, and negative or zero for households who are short in housing. As before, we use age and homeownership status to identify such households. These variables are well motivated theoretically and relatively accurately measured.

Since we are using household-level survey data, measurement error can have large effects on the coefficients that we estimate in equation (14). House prices are measured by Nationwide, and not reported by households, so measurement error is more likely to be more serious for consumption and income than for house prices. Orthogonal measurement error in income contaminates the estimated innovations to income and biases the estimate of the coefficient $\alpha_{2}$ towards zero. Alternatively, if measurement error in income is positively correlated with measurement error in consumption, 
it biases the estimate of $\alpha_{2}$ upwards. Below we interpret the results from our regression analysis in light of these possibilities. In addition, in the Appendix we report the results for robustness checks to try to minimize the impact of measurement error.

\subsection{Results for regional cohorts}

\section{Predictable changes in house prices}

The first three columns of Table 9 show estimation results for the instrumental variables regressions. All specifications include cohort and quarter fixed effects, changes in age and age squared, and changes in family size, but these coefficients are not reported. The estimated coefficients on the real interest rate and income growth variables match those typically obtained in other consumption studies, both in sign and statistical significance. The estimated coefficient for income growth is positive and statistically significant. This is the well known finding of excess sensitivity of consumption to income, which has been interpreted by Flavin (1981) and Zeldes (1989a), among others, as evidence of borrowing constraints, but that is also consistent with precautionary savings or myopic behavior (Carroll, 1997).

The novelty of our analysis is that, in addition to income, we also include predictable changes in house prices as an additional explanatory variable. Since housing is an asset that can be used as collateral an increase in house prices increases borrowing capacity, and allows borrowing-constrained homeowners to increase consumption. Interestingly, we estimate positive coefficients on house price changes, both for regional and UK house prices (specifications (i) and (ii), respectively).

However, in specification (iii) we find that regional house price changes less UK house price changes have no explanatory power beyond that of UK house price changes. This suggests that if predictable house prices affect consumption by relaxing borrowing constraints, this may be a macro effect rather than a direct channel. If homeowners in a given region are borrowing constrained, and increases in the price of their house allow them to increase consumption, we should observe regional house prices being important. Instead only aggregate house prices matter, which suggests that aggregate borrowing capacity is the relevant variable. 


\section{Unpredictable changes in house prices}

Columns (iv) through (vii) of Table 9 show results for unpredictable house price changes. As expected, the estimated coefficient on unexpected income changes is positive. Of more interest is the fact that we also estimate positive coefficients for unexpected house price changes. Moreover, and in contrast to specification (iii), unpredictable regional house price changes are statistically significant. This shows that the wealth channel through which house prices affect consumption has a regional component.

\subsection{Results for homeownership cohorts}

Predictable changes in house prices

In columns (i) through (iv) of Table 10 we examine the effects of predictable changes in house prices on the consumption of homeowners and renters. In specification (i) we find that the estimated coefficient on house prices is significantly positive so that consumption responds positively to predictable changes in house prices. In specification (ii) we include as additional dependent variables predictable house price changes interacted with dummy variables for young homeowners, young renters, and old renters. The estimated incremental effects of house prices for these three groups are all negative, but there are differences in statistical significance.

The effect of predictable house prices on the consumption of young homeowners is not statistically different from the effects of house prices on the consumption of old homeowners. Furthermore, the impact of predictable house prices on the consumption of young and old renters is significantly lower than the effects of house prices on the consumption of old homeowners, and in specification (ii) they are not statistically different from zero. In other words, we cannot reject the null hypothesis that the estimated coefficients on $\Delta p_{t}$ and $\Delta p_{t} \times$ Young Renter, and on $\Delta p_{t}$ and $\Delta p_{t} \times$ Old Renter, sum to zero. Thus the results in specification (ii) are consistent with a borrowing constraints channel that operates through changes in the collateral available to homeowners.

However, this is no longer the case once we include changes in real mortgage 
payments as an additional independent variable. In specifications (iii) and (iv) we still cannot reject the null hypothesis that the estimated coefficients on $\Delta p_{t}$ and $\Delta p_{t} \times$ Young Renter sum to zero, but we reject the hypothesis that the estimated coefficients on $\Delta p_{t}$ and $\Delta p_{t} \times$ Old Renter sum to zero. The consumption of old renters appears to respond positively to predictable changes in house prices, an effect which cannot be explained by a relaxation of household-level borrowing constraints through increased housing collateral.

This suggests that if predictable changes in house prices affect consumption through borrowing constraints, then at least for old renters it is an aggregate effect. Obviously, we cannot rule out that for homeowners the channel is a direct one, but these results combined with those for the regional cohorts point to the existence of a broader macroeconomic channel. In other words, an increase in house prices is associated with an easing of borrowing constraints in the economy as a whole, which stimulates the consumption of renters as well as homeowners. This could of course reflect reverse causality if financial liberalization drives up house prices.

There are several reasons to be cautious when comparing the magnitude of the estimated coefficients for old homeowners and old renters. First, for some of the cohorts of old renters the average cell size is relatively small. Second, renters are on average poorer than homeowners, so they may face more severe borrowing constraints. Third, the results in Table 10 may be influenced by precautionary savings effects. As Carroll (1997) has emphasized, in the presence of a precautionary savings motive the rate of growth of consumption should depend also on a variance term. ${ }^{12}$ If next period's income, house prices and consumption growth are risky, consumption now should be lower, and consumption growth should be higher. Renters tend to have lower assets, and so precautionary savings effects may be stronger for renters. Alternatively, the results in Table 10 are also consistent with a fraction of the households within the cohort exhibiting myopic behavior.

If predictable house price changes influence consumption by relaxing borrowing constraints, then the effect should be weaker for households with unused borrowing capacity. We have tested this hypothesis in two different ways. First, we have restricted the sample to households that own their houses outright, without any mortgage borrowing. For some quarters and for the very young cohorts there were no owners outright, and we dropped these observations from the analysis. For this

\footnotetext{
${ }^{12}$ See the buffer-stock models of Deaton (1991) and Carroll (1997). Carroll (1992) and Carroll and Samwick (1997) provide empirical evidence.
} 
restricted sample the estimated coefficient on predictable house price changes was positive but not significantly different from zero. Second, we have used the length of time at the present address combined with the behaviour of regional house price indices to identify homeowners with positive home equity. More precisely, we have constructed cohorts restricting the sample to homeowners whose house prices have increased by at least 10\%, 25\%, and 50\% since they first started living at their current address. The estimated coefficient on predictable house price changes decreases in size and statistical significance as we move from $10 \%$ to $25 \%$, and then to $50 \%$. The estimated coefficients (and t statistics) are respectively: 1.46 (2.94), 1.41 (2.61), 1.05 (1.62). Both these results are consistent with the hypothesis that the response of consumption to predictable house price changes is related to borrowing constraints. However, there may also be a role for precautionary savings or rule-of-thumb consumption behavior, since homeowners that have benefited from moderate $10 \%$ or $25 \%$ house price increases show some response to predictable movements in house prices.

Unpredictable changes in house prices

Columns (v) through (vii) of Table 10 estimate the effects of unpredictable house price shocks on the consumption of homeowners and renters. Recall that theory predicts that these effects should be largest and positive for old homeowners, and should be smallest and negative or zero for young renters, depending on the relative magnitude of the wealth and substitution effects. The results in Table 10 provide some empirical support for these predictions.

In specification (vi) we see that the effects of house price shocks are largest and positive for old homeowners: the estimated coefficients on house price shocks interacted with dummies for young homeowners, old renters, and young renters are all negative. Among the latter three, the estimated coefficient for young renters is largest (in absolute value) and statistically different from zero. Thus the effects of house price shocks are smallest for young renters. When we sum the estimated coefficients on innovations in $\Delta p_{t}$ and innovations in $\Delta p_{t} \times$ Young Renter we obtain a coefficient that is insignificantly different from zero.

It is also interesting that in specification (vii) we find no wealth effect of changes in mortgage payments on consumption. This is consistent with theory given that these are mostly adjustable-rate mortgages. As Campbell and Cocco (2003) show, 
an increase in expected inflation and nominal interest rates accelerates real mortgage payments on adjustable-rate mortgages. This has no wealth effect, but it may force borrowing constrained homeowners to temporarily cut back their consumption. This may be the reason why in specification (iii) we estimate a negative mortgage payment coefficient, while in specification (vii) we do not.

It is possible that some of the estimated coefficients in Table 10 are influenced by measurement error. Given that we are using house price data from Nationwide and income and consumption data from the FES, measurement error in consumption is less likely to be correlated with house prices than with income. Although we cannot rule out the possibility that measurement error affects the statistical significance or the magnitude of the estimated coefficients, it is nevertheless striking that we estimate the smallest and largest wealth effects of house prices for those households that are most likely to be short and long in housing.

\section{Conclusion}

In this paper we have used UK micro level data to estimate the response of household consumption to house prices. We have estimated the largest house price elasticity of consumption for older homeowners, and the smallest elasticity, insignificantly different from zero, for younger renters. These are the households that are most likely to gain and lose from house price increases. The estimated elasticity for the older homeowners group is as large as 1.7, controlling for interest rates, household income, and other demographic variables. This finding has macroeconomic implications since it suggests that as the population ages and becomes more concentrated in the old homeowners group, aggregate consumption may become more responsive to house prices; of course, it is possible that demographic changes will alter the stochastic processes for house prices and income, and the decision rules of households. In recent years both the UK and the US have experienced rising property prices and strong private consumption, pointing to the relevance of our estimates.

We have found, controlling for economy-wide house prices and for regional income, that regional house prices influence regional consumption. This shows that it is important to allow for regional heterogeneity when estimating the effects of house prices on consumption. 
Finally, we have found that consumption responds to predictable changes in house prices, an effect which is consistent with an increase in house prices relaxing borrowing constraints, but that may also be explained by reverse causality from financial liberalization to house prices, or by a precautionary savings motive. The consumption effects of predictable changes in house prices appear to be weaker for households that have unused borrowing capacity, but they affect both renters and homeowners and work through national rather than regional house prices. This suggests that UK house prices are related to the ease or difficulty of borrowing in the economy as a whole. 


\section{Appendix: Robustness}

\subsection{Moving probabilities and alternative cohort definitions}

Tables A.1 and A.2 report moving probabilities from one region to another, and between rental and owner-occupied housing, by age. These tables show that young households frequently switch homeownership status. In order to further address the issue of endogenous homeownership, we use a variable in the FES data which measures the length of time that the head of the household has lived at the present address. As a first approach, we restrict the sample to those households who have lived for more than six months at the present address. This means dropping five (fourteen) percent of homeowning (renting) households. We then construct cohorts of homeowners and renters for this restricted set of households, excluding households which changed homeownership status recently. ${ }^{13}$

As a second approach, we construct broader cohorts of renters, so as to include in the analysis households that switch from renters at $t-1$ to homeowners at $t$. Most households who switch from renting to homeowning do so early in life. Therefore, we have constructed cohorts of renters that include both renters who have lived at the present address for more than six months, and homeowners younger than 32 years of age who have lived at the present address for less than six months, i.e. the group of "new homeowners." We classify the latter as renters for the purpose of computing cohort averages. The cohorts of homeowners were defined as in our first approach to exclude recent movers, that is they include those who own a house and who have lived at the present address for more than six months. ${ }^{14}$

In order to investigate the extent to which the transition from renting to homeowning is correlated with house prices, and also to pick a suitable cutoff age for our definition of the new homeowners group, we have estimated the ratio of the size of the new homeowners group to the size of the renters group, for those younger than a given age. This ratio, an estimate of the transition rate from renting to home-

\footnotetext{
${ }^{13}$ Households who were renters at time $t-1$, bought the same house they were living in and became homeowners at $t$ will still be included in the sample, but there are not likely to be many such households.

${ }^{14}$ This approach still excludes households that switch from homeowners at $t-1$ to renters at $t$. Identifying such households is difficult given the nature of the data available. However, since we have restricted the sample to households with head not older than 60 years of age, these households are likely to be far fewer than those switching from renting to homeowning.
} 
owning, averages about 20 percent when we set the cutoff age to 32 . This cutoff age maximizes the correlation between the ratio and house price changes. The maximized correlation is 18 percent, but marginally insignificant with a robust p-value just above 10 percent. The significance of the correlation decreases further when we include quarter fixed effects in the regression. Thus there seems to be some evidence that the transition from renting to homeowning is positively correlated with house price changes, but the evidence is statistically weak.

Table A.3 shows estimation results for our baseline regression. Column (i) replicates the results shown in column (vi) of Table 6. Column (ii) shows the results when we restrict the sample to households who have lived at the present address for more than six months, and column (iii) shows the results when we include new homeowners as well in the cohort of renters. As can be seen from table A.1, the results in columns (ii) and (iii) are similar to those in column (i). The estimated coefficients on income changes are slightly larger, and those on house price changes slightly smaller, but they are of a similar order of magnitude. It is still the case that the effects of house prices on consumption are largest for old homeowners and smallest for young renters. Table A.4 shows that we also obtain similar results for the IV regressions and for the wealth effects of house price changes.

In this section we have used length of time at the present address to at least partially deal with the bias that may arise because of households switching homeownership status in response to house prices. In unreported results, we have used the same variable to deal with regional mobility in the definition of regional cohorts. When we restrict the sample to households who reported living at the present address for at least six months, we obtained similar results for regional cohorts.

\subsection{Other robustness checks}

We have carried out several other robustness checks which we now describe. Since the results are similar to those already reported we merely give a brief summary here. First, we have considered an expanded set of instrumental variables. In addition to the second lag of changes in consumption, income, house prices, mortgage payments, interest rate and inflation rate, we have also included the third lag of these variables. Second, we have tried to minimize the impact of measurement error by truncating the values of income and consumption changes below and above the 5th and 95th percentiles of their respective distributions, at their 5th and 95th percentile values, 
respectively. In addition, and bearing in mind that measurement error is more likely to be an issue for those cohorts whose quarter cell sizes are not very large, we have estimated regressions that weight observations by the inverse of cell size.

Third, we have expanded the dataset by constructing an unbalanced panel. Our baseline results use a pseudo-panel that is balanced in the sense that over the whole sample we have data on households with certain fixed birth years. But this means that our panel is on average thirteen years older at the end of the sample than at the beginning, and by the end of the sample we have no observations on people younger than 30. This is unfortunate since we are interested in the behavior of young renters, who are disproportionately people in their 20's.

To address this issue we have added four new cohorts of homeowners/renters that enter the dataset after 1988: two with birth year between 1970 and 1974, and two with birth year between 1975 and 1979. Obviously, there are no observations for these cohorts at the beginning of the sample period. Therefore we set them to missing values and estimate an unbalanced panel. In addition to the previously included dummy variables (young/old renters and young/old homeowners), we have created two additional dummy variables: one for the youngest renters and another for the youngest homeowners. As before we interact these dummy variables with house price changes. For a cut-off age of 28 and for the baseline regression the estimated coefficients of house price changes times the dummies for youngest homeowners and renters are both negative but not statistically significant (the $t$ statistics are around minus one). We have experimented with the cut-off age for the dummy variables for the youngest groups, but the results are not very sensitive to cut-off ages between 25 and 30. Thus we find that the effects of house prices on consumption appear to be smallest for the very young, but our estimates of these effects are not statistically significant.

Finally, we have explored whether lagged house prices affect consumption. When we include the first lag of house price growth in the regression, the estimated coefficient is negative but insignificantly different from zero. When we include both the first and second lags of house price changes the estimated coefficients on these variables are both positive, but insignificantly different from zero. In all specifications the estimated coefficient on current house price changes remains positive and statistically significant. 


\section{References}

Attanasio, Orazio P. and Martin Browning, 1995, "Consumption over the Life Cycle and Over the Business Cycle," American Economic Review 85, 1118-1137.

Attanasio, Orazio P. and Guglielmo Weber, 1994, "The Aggregate Consumption Boom of the Late 1980s: Aggregate Implications of Microeconomic Evidence," Economic Journal 104, 1269-1302.

Attanasio, Orazio P. and Guglielmo Weber, 1995, "Is Consumption Growth Consistent with Intertemporal Optimization? Evidence from the Consumer Expenditure Survey," Journal of Political Economy 103, 1121-1157.

Banks, James and Sarah Tanner, 2002, "Household Portfolios in the United Kingdom", Chapter 6 in Luigi Guiso, Michael Haliassos, and Tullio Jappelli eds., Household Portfolios, Cambridge, MA, MIT Press.

Benjamin, John, Peter Chinloy, and G. Donald Jud, 2004, "Real Estate Versus Financial Wealth in Consumption," Journal of Real Estate Finance and Economics, forthcoming.

Bertaut, Carol C. and Martha Starr-McCluer, 2002, "Household Portfolios in the United States", Chapter 5 in Luigi Guiso, Michael Haliassos, and Tullio Jappelli eds., Household Portfolios, Cambridge, MA, MIT Press.

Bhatia, Kul B., 1987, "Real Estate Assets and Consumer Spending", Quarterly Journal of Economics 102, 437-444.

Browning, Martin J., Angus S. Deaton, and Margaret Irish, 1985, "A Profitable Approach to Labor Supply and Commodity Demands Over the Life-Cycle," Econometrica, 53, 503-44.

Browning, Martin J., and Annamaria Lusardi, 1996, "Household Saving: Micro Theories and Micro Facts," Journal of Economic Literature, 34, 1797-1855.

Campbell, John Y. and João F. Cocco, 2003, "Household Risk Management and Optimal Mortgage Choice," Quarterly Journal of Economics 118, 1449-1494.

Campbell, John Y. and N. Gregory Mankiw, 1989, "Permanent Income, Current Income, and Consumption," in Olivier J. Blanchard and Stanley Fisher, eds., NBER Macroeconomics Annual, Cambridge, MA, MIT Press. 
Campbell, John Y. and N. Gregory Mankiw, 1991, "The Response of Consumption to Income," European Economic Review 35, 723-767.

Carroll, Christopher D., 1992, "The Buffer-Stock Theory of Saving: Some Macroeconomic Evidence", Brookings Papers on Economic Activity, 61-156.

Carroll, Christopher D., 1997, "Buffer-Stock Saving and the Life-Cycle/Permanent Income Hypothesis", Quarterly Journal of Economics 114, 433-495.

Carroll, Christopher D. and Andrew A. Samwick, 1997, "The Nature of Precautionary Wealth", Journal of Monetary Economics 40, 41-71.

Carroll, Christopher D. and Lawrence H. Summers, 1991, "Consumption Growth Parallels Income Growth: Some New Evidence," in B.D. Bernheim and J.B. Shoven eds., National Savings and Economic Performance, Chicago: University of Chicago Press.

Case, Karl E. and Robert J. Shiller, 1989, "The Efficiency of the Market for SingleFamily Homes," American Economic Review, 79, 125-137.

Case, Karl E., J. Quigley, and Robert J. Shiller, 2003, "Comparing Wealth Effects: The Stock Market Versus the Housing Market," unpublished paper.

Christiano, Lawrence J., Martin Eichenbaum, and David Marshall, 1991, "The Permanent Income Hypothesis Revisited," Econometrica, 59, p. 397-423.

Cocco, João F., 2005, "Portfolio Choice in The Presence of Housing," Review of Financial Studies 18, 535-567.

Deaton, Angus S., 1985, "Panel Data from a Time-Series of Cross-Sections," Journal of Econometrics 30, 109-126.

Deaton, Angus S., 1991, "Savings and Liquidity Constraints," Econometrica 59, $1221-1248$.

Deaton, Angus S., 1992, "Understanding Consumption," Oxford University Press, Oxford.

Engelhardt, Gary V., 1996, "House Prices and Home Owner Saving Behavior," Regional Science and Urban Economics 26, 313-336. 
Fernández-Villaverde, Jesús and Dirk Krueger, 2005, "Consumption over the Life Cycle: Some Facts from Consumer Expenditure Survey Data," Review of Economics and Statistics, forthcoming.

Flavin, Marjorie, 1981, "The Adjustment of Consumption to Changing Expectations About Future Income", Journal of Political Economy 89, 974-10091.

Flavin, Marjorie and Takashi Yamashita, 2002, "Owner-Occupied Housing and the Composition of the Household Portfolio", American Economic Review 92, 345362.

Goetzmann, William N., 1993, "The Single Family Home in the Investment Portfolio", Journal of Real Estate Finance and Economics 6, 201-222.

Gourinchas, Pierre-Olivier and Jonathan Parker, 2002, "Consumption Over the Life Cycle", Econometrica 70, 47-89.

Hall, Robert E., 1978, "Stochastic Implications of the Life Cycle-Permanent Hypothesis: Theory and Evidence", Journal of Political Economy 86, 971-987.

Hall, Robert E. and Frederic S. Mishkin, 1982, "The Sensitivity of Consumption to Transitory Income: Estimates From Panel Data on Households", Econometrica $50,461-481$.

Heaton, John, 1993, "The Interaction Between Time-Nonseparable Preferences and Time Aggregation", Econometrica 61, 353-385.

Lustig, Hanno and Stijn Van Nieuwerburg, 2004, "Housing Collateral and Consumption Insurance Across US Regions," unpublished paper, University of Chicago.

MaCurdy, Thomas, 1982, "The Use of Time Series Processes to Model The Error Structure of Earnings in a Longitudinal Data Analysis", Journal of Econometrics 18, 83-114.

Mankiw, N. Gregory, 1982, "Hall's Consumption Hypothesis and Durable Goods", Journal of Monetary Economics 10, 417-425.

Muellbauer, John and Anthony Murphy, 1990, "Is the UK Balance of Payments Sustainable?", Economic Policy 11, 345-383.

Muellbauer, John and Anthony Murphy, 1997, "Booms and Busts in The UK Housing Market", Economic Journal 107, 1701-1727. 
Ortalo-Magné, François and Sven Rady, 2001, "Housing Market Dynamics: On the Contribution of Income Shocks and Credit Constraints," unpublished paper, LSE.

Piazzesi, Monika, Martin Schneider, and Selale Tuzel, 2003, "Housing, Consumption, and Asset Pricing," unpublished paper, University of Chicago.

Poterba, James M., 1991, "House Price Dynamics: The Role of Tax Policy and Demography," Brookings Papers on Economic Activity 2, 143-183.

Runkle, David E., 1991, "Liquidity Constraints and the Permanent Income Hypothesis," Journal of Monetary Economics, 27, 73-98.

Sheiner, Louise, 1995, "Housing Prices and the Savings of Renters", Journal of Urban Economics 38, 94-125.

Shiller, Robert J., 1998, Macro Markets: Creating Institutions for Managing Society's Largest Economic Risks, Oxford University Press, New York, NY.

Sinai, Todd and Nicholas Souleles, 2005, "Owner-Occupied Housing as a Hedge Against Rent Risk", Quarterly Journal of Economics, 120, 763-789.

Skinner, Jonathan, 1989, "Housing Wealth and Aggregate Saving", Regional Science and Urban Economics 19, 305-324.

Skinner, Jonathan, 1994, "Housing and Saving in the United States", in Yukio Noguchi and James M. Poterba eds. Housing Markets in the United States and Japan, University of Chicago Press, Chicago, IL, 191-213.

Tracy, Joseph and Henry Schneider, 2001, "Stocks in the Household Portfolio: A Look Back at the 1990's", Current Issues in Economics and Finance 7(4) (Federal Reserve Bank of New York, New York, NY), 1-6.

Yao, Rui and Harold H. Zhang, 2005, "Optimal Consumption and Portfolio Choices with Risky Housing and Borrowing Constraints," Review of Financial Studies 18, 197-239.

Yogo, Motohiro, 2003, "A Consumption-Based Explanation of Expected Stock Returns", unpublished paper, Harvard University.

Zeldes, Stephen, 1989a, "Consumption and Liquidity Constraints: An Empirical Investigation", Journal of Political Economy 97, 305-346. 
Zeldes, Stephen, 1989b, "Optimal Consumption with Stochastic Income: Deviations from Certainty Equivalence", Quarterly Journal of Economics 104, 275-298. 


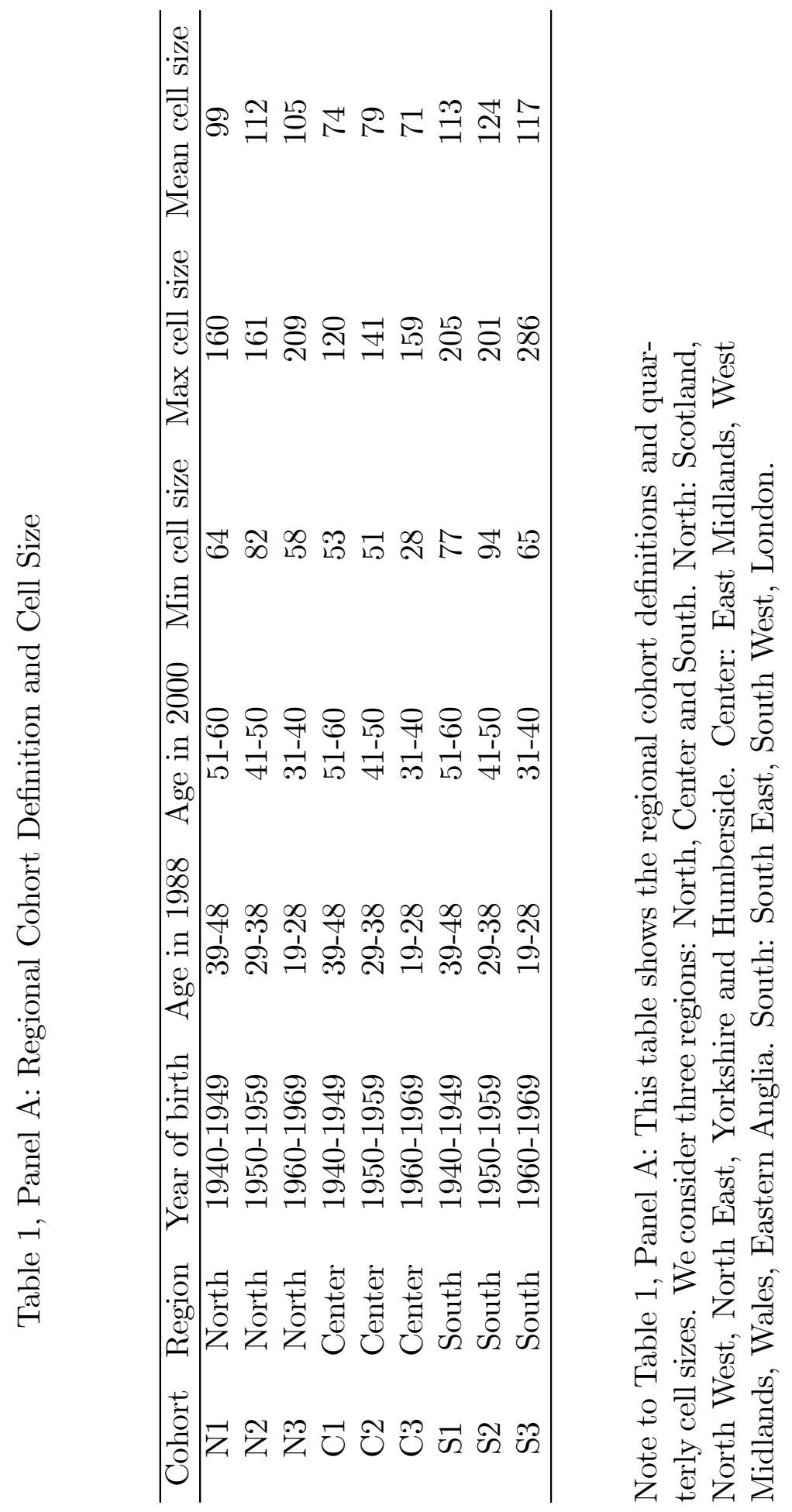




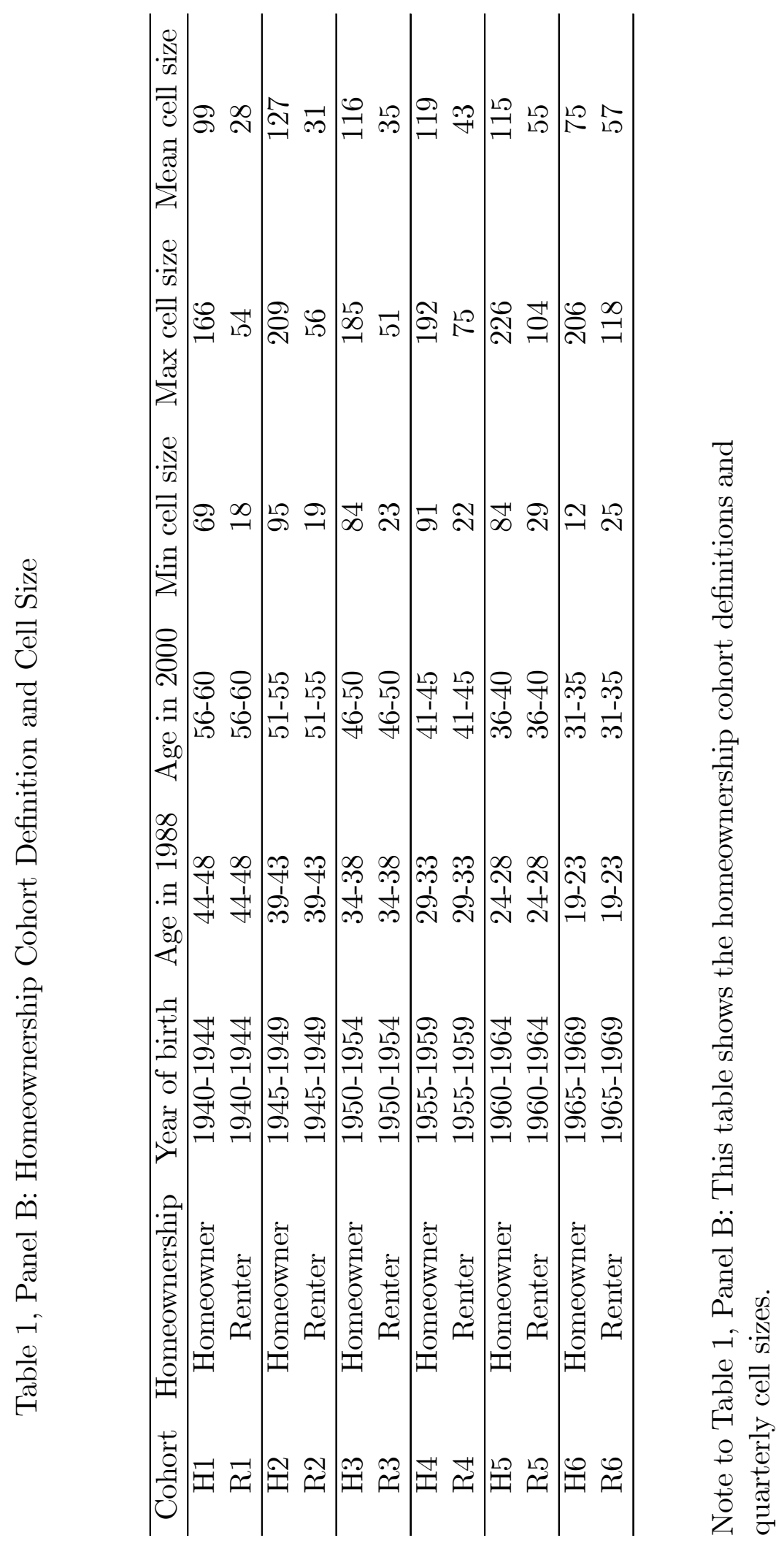


Table 2, Panel A: Cohort Mean Data Summary for Regional Cohorts.

\begin{tabular}{lccc}
\hline Variable & Mean & Min & Max \\
\hline \multicolumn{4}{c}{ North } \\
$\Delta c$ & 0.327 & -52.377 & 58.865 \\
$\Delta y$ & 0.413 & -38.768 & 49.111 \\
$\Delta m$ & 0.325 & -38.604 & 37.708 \\
Family size & 2.564 & 1.558 & 3.401 \\
\hline \multicolumn{4}{c}{ Center } \\
$\Delta c$ & 0.386 & -44.617 & 51.261 \\
$\Delta y$ & 0.332 & -51.387 & 55.881 \\
$\Delta m$ & 0.453 & -32.799 & 38.689 \\
Family size & 2.632 & 1.521 & 3.441 \\
\hline \multicolumn{4}{c}{ South } \\
$\Delta c$ & 0.489 & -50.052 & 54.368 \\
$\Delta y$ & 0.515 & -37.129 & 49.516 \\
$\Delta m$ & 0.225 & -31.136 & 32.878 \\
Family size & 2.511 & 1.558 & 3.178 \\
\hline
\end{tabular}

Note to Table 2, Panel A: First differences are all percentage points per quarter. $c$ denotes log consumption, $y$ denotes log income, $m$ denotes the log of mortgage payments for the sample of mortgage borrowers. Family size is the number of adults plus children in the household. This panel shows summary statistics for the regional cohorts defined in Table 1, Panel A. 
Table 2, Panel B: Cohort Mean Data Summary for Homeownership Cohort Definition.

\begin{tabular}{lccc}
\hline Variable & Mean & Min & Max \\
\hline \multicolumn{4}{c}{ Renters } \\
$\Delta c$ & -0.485 & -54.157 & 44.901 \\
$\Delta y$ & -0.082 & -60.956 & 75.190 \\
Family size & 2.314 & 1.270 & 3.667 \\
\hline \multicolumn{4}{c}{ Homeowners } \\
$\Delta c$ & 0.611 & -55.743 & 66.204 \\
$\Delta y$ & 0.401 & -39.140 & 49.224 \\
Family size & 2.547 & 1.642 & 3.428 \\
\hline
\end{tabular}

Note to Table 2, Panel B: First differences are all percentage points per quarter. $c$ denotes $\log$ consumption and $y$ denotes log income. Family size is the number of adults plus children in the household. This panel shows summary statistics for the homeownership cohorts defined in Table 1, Panel B. 
Table 3: Summary Statistics and Correlation Matrix for Quarterly (Annual) Log House Price Returns

\begin{tabular}{lccc}
\hline Region & North & Center & South \\
\hline Mean & $1.27(4.43)$ & $1.23(3.42)$ & $0.94(2.84)$ \\
St Dev & $3.04(9.11)$ & $3.80(9.83)$ & $3.59(10.02)$ \\
Min & $-3.47(-5.45)$ & $-4.43(-11.15)$ & $-6.26(-16.22)$ \\
Max & $9.69(33.95)$ & $14.70(42.54)$ & $9.83(21.50)$ \\
\hline \multicolumn{4}{c}{ Correlation Matrix } \\
North & North & Center & South \\
Center & $0.62(0.80)$ & 1.00 & $0.72(0.77)$ \\
South & $0.30(0.35)$ & 1.00 \\
\hline
\end{tabular}

Note to Table 3: This table shows summary statistics and correlation between quarterly (annual) house price returns for the three UK regions that we consider: North, Center and South. North: Scotland, North West, North East, Yorkshire and Humberside. Center: East Midlands, West Midlands, Wales, Eastern Anglia. South: South East, South West, London. 


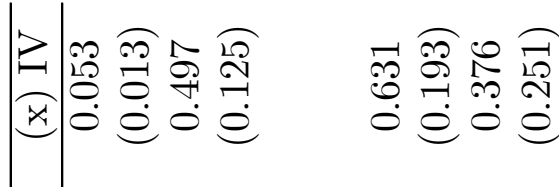

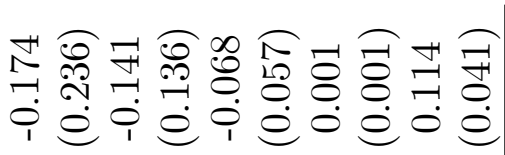

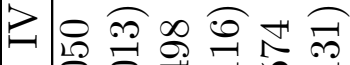

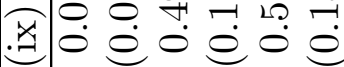

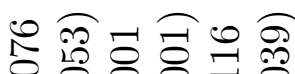

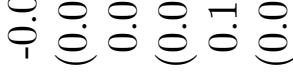

:

$\forall 0$

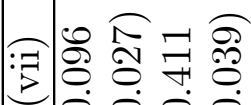

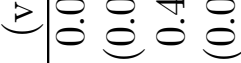

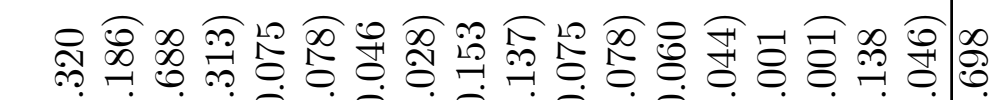

赵

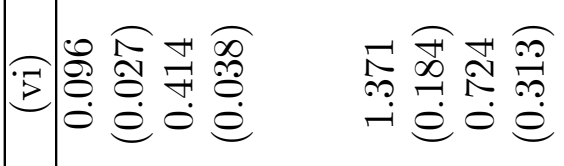

డే

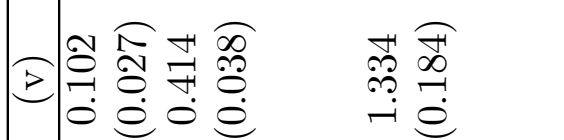

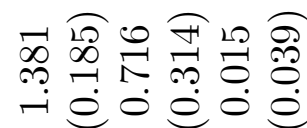

次

官

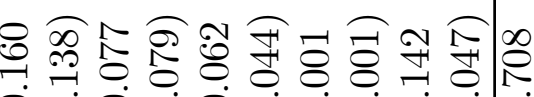

节

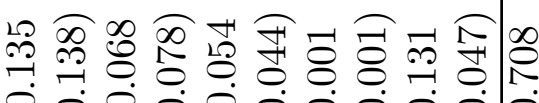

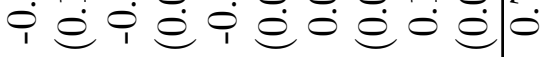

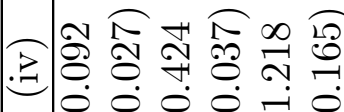

속 슥

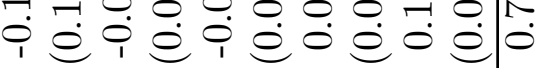

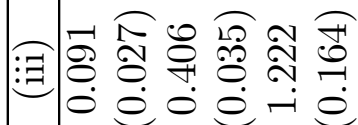

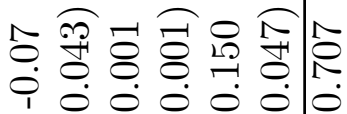

웡ㅇㅇ

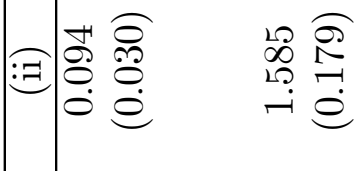

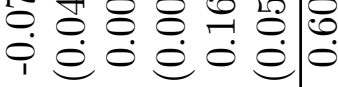

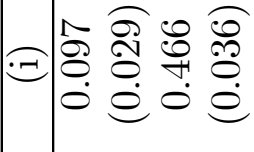

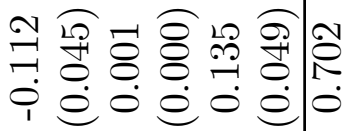

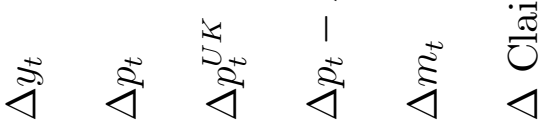

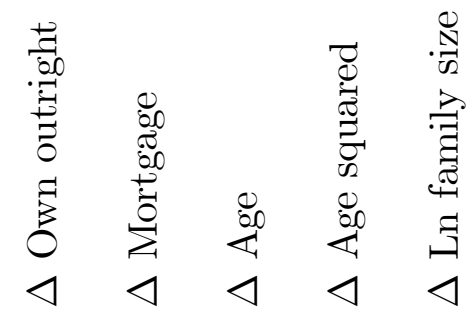


Note to Table 4: The dependent variable is $\Delta c_{t}$, where $c$ is the log of real non-durable consumption. The independent variables include the real interest rate, quarterly growth of household income, and quarterly growth of house prices, both regional $(\Delta p)$ and national $\left(\Delta p^{U K}\right) . \Delta p-\Delta p^{U K}$ is the difference between regional and national house price growth. $\Delta m$ is the growth in real mortgage payments. $\Delta$ Own outright ( $\Delta$ Mortgage) is the difference in the proportion of homeowners outright (with a mortgage). $\Delta$ Claimants count is the change in the regional claimants count rate, a proxy for the regional unemployment rate. The equation was estimated using synthetic cohort techniques and data for regional cohorts. All regressions include quarter dummies and cohort dummies (not reported). The standard errors shown in parentheses are corrected for heteroscedasticity and first order serial correlation. The last two columns report instrumental variables regression results, with $\Delta y_{t}$ instrumented using the regional claimants count rate, changes in house prices, and the second lag of changes in income. 


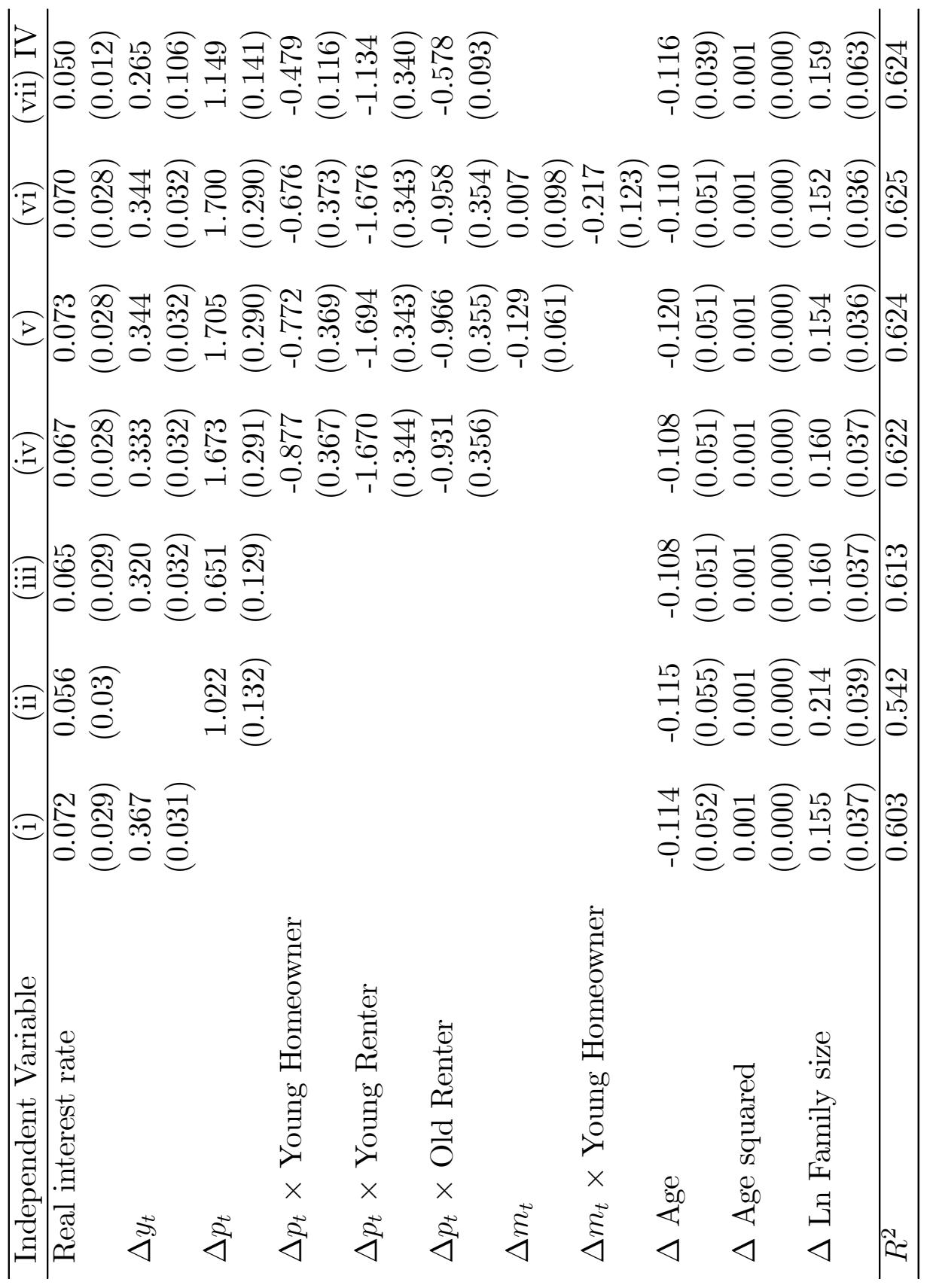


Note to Table 5: The dependent variable is $\Delta c_{t}$, where $c$ is the log of real non-durable consumption. The independent variables include the real interest rate, quarterly growth in household income, quarterly growth in house prices $(\Delta p)$, quarterly growth in house prices interacted with dummy variables for young homeowners and young and old renters, and quarterly growth in mortgage payments $\left(\Delta m_{t}\right)$, also interacted with a dummy for young homeowner. Young (old) are those younger (older) than 40 years of age. The equation was estimated using synthetic cohort techniques and data for the the cohorts of homeowners and renters. All regressions include quarter dummies and cohort dummies (not reported). The standard errors shown in parentheses are corrected for heteroscedasticity and first order serial correlation. The last column reports instrumental variables regression results, with $\Delta y_{t}$ instrumented using the regional claimants count rate, changes in house prices, and the second lag of changes in income. 
Table 6: Calibrated and estimated parameters

\begin{tabular}{lcc}
\hline Description & Parameter & Value \\
\hline Risk aversion & $\gamma$ & 3 \\
Discount factor & $\beta$ & .98 \\
Preference for housing & $\theta$ & 1.00 \\
Bequest motive & $b$ & 1.00 \\
Downpayment ratio & $d$ & .15 \\
Transaction cost & $\lambda$ & .08 \\
Moving probability & $\pi$ & .05 \\
Interest rate & $R$ & .01 \\
Rental Premium & $\theta^{R}$ & .01 \\
Mean log real house price growth & $g$ & .01 \\
S.d. of log real house price growth & $\sigma_{\delta}$ & .062 \\
\hline S.d. of transitory income shocks & $\sigma_{\omega}$ & .100 \\
S.d. of persistent income shocks & $\sigma_{\eta}$ & .030 \\
\hline
\end{tabular}

Note to Table 6: All parameters are in annual terms. The income data are from the FES from 1988 through 1999. The house price data are from Nationwide from 1962 to 1999. 
Table 7: BHPS Data and Simulated Data

\begin{tabular}{|c|c|c|c|}
\hline \multicolumn{4}{|c|}{ Panel A: BHPS Data } \\
\hline & \multicolumn{3}{|c|}{ Age Group } \\
\hline & $20-39$ & $40-59$ & $60-79$ \\
\hline Fraction homeowners & 0.61 & 0.78 & 0.66 \\
\hline Annual moving probability & 0.17 & 0.04 & 0.03 \\
\hline Annual mov. prob. renters & 0.23 & 0.07 & 0.04 \\
\hline Annual mov. prob. homeowners & 0.12 & 0.04 & 0.02 \\
\hline \multicolumn{4}{|c|}{ Panel B: Heterogeneous discount rate model } \\
\hline & \multicolumn{3}{|c|}{ Age Group } \\
\hline & $20-39$ & $40-59$ & 60-79 \\
\hline Fraction homeowners & 0.24 & 0.68 & 0.59 \\
\hline Annual moving probability & 0.21 & 0.10 & 0.08 \\
\hline Annual mov. prob. renters & 0.23 & 0.22 & 0.10 \\
\hline Annual mov. prob. homeowners & 0.05 & 0.05 & 0.07 \\
\hline \multirow{2}{*}{\multicolumn{4}{|c|}{$\begin{array}{c}\text { Panel C: Heterogeneous moving probability model } \\
\text { Age Group }\end{array}$}} \\
\hline & & & \\
\hline & $20-39$ & $40-59$ & 60-79 \\
\hline Fraction homeowners & 0.26 & 0.76 & 0.63 \\
\hline Annual moving probability & 0.20 & 0.09 & 0.09 \\
\hline Annual mov. prob. renters & 0.21 & 0.17 & 0.13 \\
\hline Annual mov. prob. homeowners & 0.05 & 0.06 & 0.08 \\
\hline
\end{tabular}

Note to Table 7: This table shows the proportion of homeowners, annual unconditional moving probability, and moving probability conditional on homeownership status, by age. Panel A shows the data from the British Household Panel Survey. Panels B and $\mathrm{C}$ show the results obtained from simulated data. Panel B shows the results for 70 percent of the households facing the baseline parameters shown in Table 9, and for the remaining 30 percent facing the same parameters except for a lower discount factor equal to 0.85 . Panel $\mathrm{C}$ shows the results for 70 percent of the households facing the baseline parameters shown in Table 9, and for the remaining 30 percent facing the same parameters except for a higher moving probability equal to 0.10 . 
Table 8: Estimation results based on simulated data

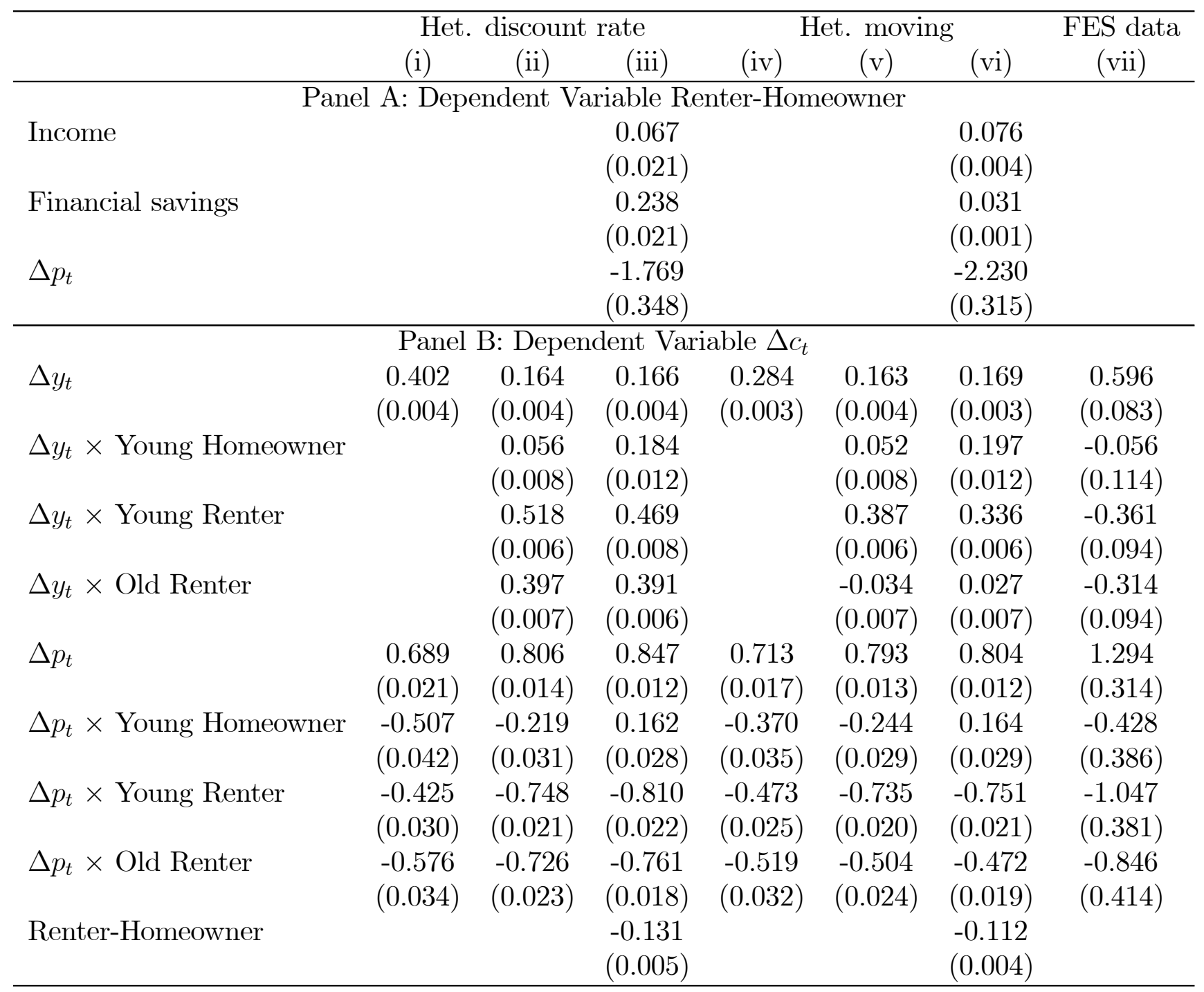


Note to Table 8: The dependent variable in Panel A is a dummy variable that takes the value of one in periods in which the household switches from renting to owning, and zero otherwise. The independent variables include household income, financial savings, and the growth in house prices $(\Delta p)$. The dependent variable in Panel $\mathrm{B}$ is $\Delta c_{t}$, where $c$ is the log of real non-durable consumption. The independent variables include the growth in household income, growth in house prices $(\Delta p)$, growth in income and house prices interacted with dummy variables for young homeowners, young renters, and old renters. Young are those younger than 40 years of age. Old are those older than 40 years of age, but younger than 60 years of age. We also include as independent variables a second order polynomial of age (estimated coefficients not reported). In columns (i) through (iv) the data were generated by the model with 70 percent of the households facing the baseline parameters shown in Table 6, and the remaining 30 percent facing the same parameters except for a lower discount factor equal to 0.85 . In columns (v) through (viii) the data were generated by the model with 70 percent of the households facing the baseline parameters shown in Table 6, and the remaining 30 percent facing the same parameters except for a higher moving probability equal to 0.10 . In columns (i), (ii), (v) and (vi) we estimate regressions similar to those that we have estimated on the data, i.e. without controlling for the endogeneity of the decision of whether to become a homeowner. In columns (iii), (iv), (vii) and (viii) we estimate jointly the decision to become a homeowner, and the impact of house price changes on consumption. Both equations include as independent variables a second order polynomial on age. 
Table 9: Predictable and Unpredictable Effects for Regional Cohorts

\begin{tabular}{|c|c|c|c|c|c|c|}
\hline \multirow[b]{2}{*}{ Independent Variable } & \multicolumn{3}{|c|}{ Predictable Effects } & \multicolumn{3}{|c|}{ Unpredictable Effects } \\
\hline & (i) & (ii) & (iii) & (iv) & $(\mathrm{v})$ & (vi) \\
\hline \multirow[t]{2}{*}{ Real interest rate } & 0.092 & 0.120 & 0.129 & & & \\
\hline & $(0.063)$ & $(0.062)$ & $(0.064)$ & & & \\
\hline \multirow[t]{2}{*}{$\Delta y_{t}$} & 0.497 & 0.526 & 0.549 & & & \\
\hline & $(0.215)$ & $(0.210)$ & $(0.214)$ & & & \\
\hline \multirow[t]{2}{*}{$\Delta p_{t}$} & 1.950 & & & & & \\
\hline & $(0.499)$ & & & & & \\
\hline \multirow{2}{*}{$\Delta p_{t}^{U K}$} & & 2.506 & 2.451 & & & \\
\hline & & $(0.517)$ & $(0.525)$ & & & \\
\hline \multirow[t]{2}{*}{$\Delta p_{t}-\Delta p_{t}^{U K}$} & & & -0.599 & & & \\
\hline & & & $(1.008)$ & & & \\
\hline \multirow[t]{2}{*}{ Innov. in real interest rate } & & & & 0.074 & 0.080 & 0.076 \\
\hline & & & & $(0.026)$ & $(0.026)$ & $(0.026)$ \\
\hline \multirow[t]{2}{*}{ Innov. in income } & & & & 0.420 & 0.417 & 0.416 \\
\hline & & & & $(0.036)$ & $(0.037)$ & $(0.037)$ \\
\hline \multirow[t]{2}{*}{ Innov. in $\Delta p_{t}$} & & & & 0.794 & & \\
\hline & & & & $(0.160)$ & & \\
\hline \multirow[t]{2}{*}{ Innov. in $\Delta p_{t}^{U K}$} & & & & & 0.842 & 0.867 \\
\hline & & & & & $(0.182)$ & $(0.182)$ \\
\hline \multirow[t]{2}{*}{ Innov. in $\Delta p_{t}-\Delta p_{t}^{U K}$} & & & & & & 0.585 \\
\hline & & & & & & $(0.293)$ \\
\hline
\end{tabular}


Note to Table 9: In specifications (i) through (iii) the dependent variable is $\Delta c_{t}$, where $c$ is the log of real non-durable consumption. The independent variables include the real interest rate, quarterly growth in household income, and quarterly growth in house prices, both regional $(\Delta p)$ and national $\left(\Delta p^{U K}\right) . \Delta p-\Delta p^{U K}$ is the difference between regional and national house price growth. The regressions include changes in age, age squared, changes in family size, quarter dummies and cohort dummies (not reported). The equation was estimated using synthetic cohort techniques and instrumental variables. The instruments used were the second lag of changes in non-durable consumption, income, regional and national house prices, the second lags of nominal interest rates and inflation, and the second lag of changes in family size. In specifications (iv) through (vi) the independent variables are the innovations in income, house prices and real interest rate obtained as the residual of the first stage regressions in the IV estimation. The standard errors are corrected for heteroscedasticity and first-order serial correlation. 
Table 10: Predictable and Unpredictable Effects for Homeownership Cohorts

\begin{tabular}{|c|c|c|c|c|c|c|c|}
\hline \multirow[b]{2}{*}{ Independent Variable } & \multicolumn{4}{|c|}{ Predictable Effects } & \multicolumn{3}{|c|}{ Unpredictable Effects } \\
\hline & (i) & (ii) & (iii) & (iv) & $(\mathrm{v})$ & (vi) & (vii) \\
\hline Real interest rate & $\begin{array}{c}0.171 \\
(0.065)\end{array}$ & $\begin{array}{c}0.183 \\
(0.065)\end{array}$ & $\begin{array}{c}0.120 \\
(0.069)\end{array}$ & $\begin{array}{c}0.126 \\
(0.069)\end{array}$ & & & \\
\hline$\Delta y_{t}$ & $\begin{array}{c}0.331 \\
(0.122)\end{array}$ & $\begin{array}{c}0.392 \\
(0.122)\end{array}$ & $\begin{array}{c}0.369 \\
(0.121)\end{array}$ & $\begin{array}{c}0.377 \\
(0.122)\end{array}$ & & & \\
\hline$\Delta p_{t}$ & $\begin{array}{c}1.573 \\
(0.731)\end{array}$ & $\begin{array}{c}3.280 \\
(0.916)\end{array}$ & $\begin{array}{c}4.164 \\
(0.974)\end{array}$ & $\begin{array}{l}4.139 \\
(0.974)\end{array}$ & & & \\
\hline$\Delta p_{t} \times$ Young Owner & & $\begin{array}{l}-1.353 \\
(0.872)\end{array}$ & $\begin{array}{l}-1.354 \\
(0.868)\end{array}$ & $\begin{array}{l}-1.415 \\
(0.871)\end{array}$ & & & \\
\hline$\Delta p_{t} \times$ Young Renter & & $\begin{array}{l}-2.719 \\
(0.825)\end{array}$ & $\begin{array}{l}-2.791 \\
(0.821)\end{array}$ & $\begin{array}{l}-2.728 \\
(0.825)\end{array}$ & & & \\
\hline$\Delta p_{t} \times$ Old Renter & & $\begin{array}{l}-2.256 \\
(0.832)\end{array}$ & $\begin{array}{l}-2.377 \\
(0.829)\end{array}$ & $\begin{array}{l}-2.363 \\
(0.829)\end{array}$ & & & \\
\hline$\Delta m_{t}$ & & & $\begin{array}{l}-0.669 \\
(0.260)\end{array}$ & $\begin{array}{l}-0.455 \\
(0.363)\end{array}$ & & & \\
\hline$\Delta m_{t} \times$ Young Owner & & & & $\begin{array}{l}-0.342 \\
(0.406)\end{array}$ & & & \\
\hline Innov. in real interest rate & & & & & $\begin{array}{c}0.049 \\
(0.028)\end{array}$ & $\begin{array}{c}0.053 \\
(0.028)\end{array}$ & $\begin{array}{c}0.056 \\
(0.028)\end{array}$ \\
\hline Innov. in income & & & & & $\begin{array}{c}0.349 \\
(0.033)\end{array}$ & $\begin{array}{c}0.350 \\
(0.033)\end{array}$ & $\begin{array}{c}0.355 \\
(0.034)\end{array}$ \\
\hline Innov. in $\Delta p_{t}$ & & & & & $\begin{array}{c}0.519 \\
(0.129)\end{array}$ & $\begin{array}{c}1.108 \\
(0.325)\end{array}$ & $\begin{array}{c}1.112 \\
(0.328)\end{array}$ \\
\hline Innov. in $\Delta p_{t} \times$ Young Homeowner & & & & & & $\begin{array}{l}-0.463 \\
(0.416)\end{array}$ & $\begin{array}{l}-0.348 \\
(0.429)\end{array}$ \\
\hline Innov. in $\Delta p_{t} \times$ Young Renter & & & & & & $\begin{array}{l}-1.097 \\
(0.388)\end{array}$ & $\begin{array}{l}-1.107 \\
(0.390)\end{array}$ \\
\hline Innov. in $\Delta p_{t} \times$ Old Renter & & & & & & $\begin{array}{l}-0.403 \\
(0.396)\end{array}$ & $\begin{array}{l}-0.411 \\
(0.399)\end{array}$ \\
\hline Innov. in $\Delta m_{t}$ & & & & & & & $\begin{array}{l}-0.010 \\
(0.095)\end{array}$ \\
\hline Innov. in $\Delta m_{t} \times$ Young Homeowner & & & & & & & $\begin{array}{l}-0.098 \\
(0.126)\end{array}$ \\
\hline
\end{tabular}


Note to Table 10: In specifications (i) through (iv) the dependent variable is $\Delta c_{t}$, where $c$ is the log of real non-durable consumption. The independent variables include the real interest rate, quarterly growth in household income, quarterly growth in house prices, also interacted with dummies for young homeowners and young and old renters, and quarterly changes in mortgage payments, also interacted with a dummy for young homeowners. The regressions include changes in age, age squared, changes in family size, quarter dummies and cohort dummies (not reported). The equation was estimated using synthetic cohort techniques and instrumental variables. The instruments used were the second lag of changes in non-durable consumption, income, regional and national house prices, the second lags of nominal interest rates and inflation, and the second lag of changes in family size. In specifications (v) through (vii) the independent variables are the innovations in income, house prices and real interest rate obtained as the residual of the first stage regressions in the IV estimation. The standard errors are corrected for heteroscedasticity and first-order serial correlation. 
Table A.1: Regional Transition Probabilities: North (N), Center (C), South (S).

\begin{tabular}{l|ccc|ccc|ccc}
\hline Age Group & N-N & N-C & N-S & C-N & C-C & C-S & S-N & S-C & S-S \\
\hline $20-24$ & 0.960 & 0.029 & 0.011 & 0.000 & 1.000 & 0.000 & 0.000 & 0.000 & 0.994 \\
$25-29$ & 0.992 & 0.004 & 0.003 & 0.008 & 0.980 & 0.008 & 0.008 & 0.011 & 0.981 \\
$30-34$ & 0.993 & 0.002 & 0.005 & 0.005 & 0.990 & 0.004 & 0.003 & 0.007 & 0.991 \\
$35-39$ & 0.991 & 0.004 & 0.004 & 0.000 & 0.990 & 0.008 & 0.002 & 0.006 & 0.991 \\
$40-44$ & 0.997 & 0.001 & 0.001 & 0.003 & 0.990 & 0.005 & 0.001 & 0.003 & 0.995 \\
$45-49$ & 0.994 & 0.003 & 0.003 & 0.001 & 0.996 & 0.003 & 0.000 & 0.004 & 0.996 \\
$50-54$ & 0.998 & 0.000 & 0.000 & 0.003 & 0.992 & 0.003 & 0.001 & 0.001 & 0.998 \\
$55-59$ & 0.998 & 0.002 & 0.000 & 0.000 & 0.998 & 0.002 & 0.000 & 0.004 & 0.996 \\
$60-64$ & 0.997 & 0.002 & 0.002 & 0.000 & 1.000 & 0.000 & 0.000 & 0.006 & 0.992 \\
$65-69$ & 1.000 & 0.000 & 0.000 & 0.003 & 0.997 & 0.000 & 0.001 & 0.000 & 0.998 \\
$70-74$ & 0.998 & 0.002 & 0.000 & 0.000 & 0.997 & 0.003 & 0.000 & 0.000 & 1.000 \\
$75-79$ & 0.996 & 0.002 & 0.002 & 0.000 & 0.998 & 0.002 & 0.000 & 0.004 & 0.996 \\
$80-84$ & 1.000 & 0.000 & 0.000 & 0.000 & 0.988 & 0.009 & 0.000 & 0.002 & 0.998 \\
$85-89$ & 1.000 & 0.000 & 0.000 & 0.000 & 0.990 & 0.010 & 0.000 & 0.000 & 1.000 \\
\hline
\end{tabular}

Note to Table A.1: This table shows annual transition probabilities for households living in different regions, North $(\mathrm{N})$, Center (C), and South (S), for different age groups. The data are from the British Household Panel Survey for the years 1991 to 1999. North (N): Scotland, North West, North East, Yorkshire and Humberside. Center (C): East Midlands, West Midlands, Wales, Eastern Anglia. South (S): South East, South West, London. 
Table A.2: Renter (R)/Homeowner(H) Transition Probabilities

\begin{tabular}{l|cc|cc|cc|c}
\hline Age Group & R-R & R-H & H-R & H-H & Frac. R & Frac. H & Mean Cell Size \\
\hline $20-24$ & 0.877 & 0.123 & 0.065 & 0.935 & 0.60 & 0.40 & 84 \\
$25-29$ & 0.888 & 0.112 & 0.046 & 0.954 & 0.40 & 0.60 & 287 \\
$30-34$ & 0.910 & 0.090 & 0.026 & 0.974 & 0.31 & 0.69 & 530 \\
$35-39$ & 0.914 & 0.086 & 0.013 & 0.987 & 0.26 & 0.74 & 643 \\
$40-44$ & 0.941 & 0.059 & 0.010 & 0.990 & 0.23 & 0.77 & 615 \\
$45-49$ & 0.964 & 0.036 & 0.005 & 0.995 & 0.21 & 0.79 & 581 \\
$50-54$ & 0.942 & 0.058 & 0.006 & 0.994 & 0.21 & 0.79 & 495 \\
$55-59$ & 0.965 & 0.035 & 0.004 & 0.996 & 0.23 & 0.77 & 411 \\
$60-64$ & 0.985 & 0.015 & 0.005 & 0.995 & 0.27 & 0.73 & 391 \\
$65-69$ & 0.984 & 0.016 & 0.006 & 0.994 & 0.32 & 0.68 & 447 \\
$70-74$ & 0.983 & 0.017 & 0.002 & 0.998 & 0.37 & 0.63 & 478 \\
$75-79$ & 0.991 & 0.009 & 0.006 & 0.994 & 0.41 & 0.59 & 368 \\
$80-84$ & 0.996 & 0.004 & 0.013 & 0.987 & 0.47 & 0.53 & 261 \\
$85-89$ & 0.988 & 0.012 & 0.015 & 0.985 & 0.55 & 0.45 & 133 \\
\hline
\end{tabular}

Note to Table A.2: This table shows annual transition probabilities from renter to renter, renter to homeowner, homeowner to renter, and homeowner to homeowner for different age groups. The table also shows the proportion of homeowners and renters. The data are from the British Household Panel Survey for the years 1991 to 1999 . 
Table A.3: Endogeneity of Homeownership: Benchmark Regression Results.

\begin{tabular}{lccc}
\hline Independent Variable & $(\mathrm{i})$ & (ii) & (iii) \\
\hline Real interest rate & 0.070 & 0.076 & 0.075 \\
& $(0.028)$ & $(0.028)$ & $(0.027)$ \\
$\Delta y_{t}$ & 0.344 & 0.360 & 0.371 \\
& $(0.032)$ & $(0.032)$ & $(0.032)$ \\
$\Delta p_{t}$ & 1.700 & 1.705 & 1.652 \\
$\Delta p_{t} \times$ Young Homeowner & $(0.290)$ & $(0.292)$ & $(0.283)$ \\
& -0.676 & -0.636 & -0.631 \\
$\Delta p_{t} \times$ Young Renter & $(0.373)$ & $(0.368)$ & $(0.358)$ \\
& -1.676 & -1.827 & -1.655 \\
$\Delta p_{t} \times$ Old Renter & $(0.343)$ & $(0.339)$ & $(0.336)$ \\
& -0.958 & -1.097 & -1.078 \\
$\Delta m_{t}$ & $(0.354)$ & $(0.354)$ & $(0.345)$ \\
$\Delta m_{t} \times$ Young Homeowner & 0.007 & 0.015 & 0.014 \\
$\Delta$ Age & $-0.098)$ & $(0.098)$ & $(0.095)$ \\
& $(0.123)$ & -0.175 & -0.179 \\
$\Delta$ Age squared & -0.110 & -0.105 & $(0.119)$ \\
& $(0.051)$ & $(0.051)$ & $(0.089$ \\
$\Delta$ Ln Family size & 0.001 & 0.001 & 0.001 \\
& $(0.000)$ & $(0.000)$ & $(0.000)$ \\
\hline$R^{2}$ & 0.152 & 0.165 & 0.178 \\
& $(0.036)$ & $(0.036)$ & $(0.036)$ \\
\hline
\end{tabular}


Note to Table A.3: The dependent variable is $\Delta c_{t}$, where $c$ is the $\log$ of real nondurable consumption. The independent variables include the real interest rate, quarterly changes in household income, quarterly changes in house prices $(\Delta p)$, quarterly changes in house prices interacted with dummy variables for young homeowners, and young and old renters, and quarterly changes in mortgage payments $\left(\Delta m_{t}\right)$, also interacted with a dummy for young homeowners. Young (old) are those younger (older) than forty years of age. The equation was estimated using synthetic cohort techniques and data for the the cohorts of homeowners and renters. The columns differ in the way the cohorts of homeowners and renters are defined. In (i) homeowners (renters) in quarter $t$ are those who reported being homeowners (renters) in that quarter. In (ii) homeowners (renters) are those who reported being homeowners (renters) in quarter $t$ and who reported living at the current address for at least six months. In (iii) homeowners (renters) are those who reported being homeowners (renters) in quarter $t$ and who reported living at the current address for at least six months. In addition in (iii) we classify as renters those who reported being homeowners who have lived at their present address for less than six months and who are younger than 32 years of age.

All regressions include quarter dummies and cohort dummies (not reported). The standard errors shown in parentheses are corrected for heteroscedasticity and first order serial correlation. 
Table A.4, Panel A: Endogeneity of Homeownership: IV Regressions.

\begin{tabular}{lccc}
\hline Independent Variable & (i) & (ii) & (iii) \\
\hline Real interest rate & 0.120 & 0.137 & 0.117 \\
& $(0.069)$ & $(0.076)$ & $(0.073)$ \\
$\Delta y_{t}$ & 0.369 & 0.354 & 0.391 \\
& $(0.121)$ & $(0.118)$ & $(0.125)$ \\
$\Delta p_{t}$ & 4.164 & 3.822 & 3.533 \\
& $(0.974)$ & $(0.919)$ & $(0.927)$ \\
$\Delta p_{t} \times$ Young Homeowner & -1.354 & -1.136 & -1.198 \\
& $(0.868)$ & $(0.868)$ & $(0.872)$ \\
$\Delta p_{t} \times$ Young Renter & -2.791 & -2.982 & -2.635 \\
& $(0.821)$ & $(0.821)$ & $(0.839)$ \\
$\Delta p_{t} \times$ Old Renter & -2.377 & -2.344 & -2.372 \\
& $(0.829)$ & $(0.832)$ & $(0.838)$ \\
$\Delta m_{t}$ & -0.669 & -0.483 & -0.488 \\
& $(0.260)$ & $(0.330)$ & $(0.330)$ \\
\hline
\end{tabular}

Table A.4, Panel B: Endogeneity of Homeownership: Wealth Effects.

\begin{tabular}{lccc}
\hline Independent Variable & (iv) & (v) & (vi) \\
\hline Innov. in real int. rate & 0.056 & 0.062 & 0.062 \\
& $(0.028)$ & $(0.028)$ & $(0.028)$ \\
Innov. in income & 0.355 & 0.379 & 0.390 \\
& $(0.034)$ & $(0.035)$ & $(0.034)$ \\
Innov. in $\Delta p_{t}$ & 1.112 & 1.076 & 1.068 \\
& $(0.328)$ & $(0.331)$ & $(0.321)$ \\
In. in $\Delta p_{t} \times$ Young Homeowner & -0.348 & -0.264 & -0.277 \\
& $(0.429)$ & $(0.430)$ & $(0.417)$ \\
In. in $\Delta p_{t} \times$ Young Renter & -1.107 & -1.211 & -1.057 \\
In. in $\Delta p_{t} \times$ Old Renter & $(0.390)$ & $(0.387)$ & $(0.379)$ \\
& -0.411 & -0.563 & -0.559 \\
In. in $\Delta m_{t}$ & $(0.399)$ & $(0.402)$ & $(0.390)$ \\
In. In $\Delta m_{t} \times$ Young Homeowner & -0.010 & 0.023 & 0.024 \\
& $(0.095)$ & $(0.094)$ & $(0.091)$ \\
& $(0.126)$ & -0.117 & -0.133 \\
& & & \\
\hline
\end{tabular}


Note to Table A.4: In specifications (i) through (iii) the dependent variable is $\Delta c_{t}$, where $c$ is the log of real non-durable consumption. The independent variables include the real interest rate, quarterly growth in household income, quarterly growth in house prices $(\Delta p)$, also interacted with dummies for young homeowners and young and old renters, and quarterly changes in mortgage payments $\left(\Delta m_{t}\right)$. The regressions include changes in age, age squared, changes in family size, quarter dummies and cohort dummies (not reported). The equations were estimated using synthetic cohort techniques and instrumental variables. The instruments used were the second lag of changes in non-durable consumption, income, house prices, mortgage payments, the second lag of nominal interest rates and inflation, and the second lag of changes in family size. In columns (iv) through (vi) the dependent variable is the innovation in $\Delta c_{t}$. The independent variables are the innovations in income, house prices, the real interest rate, and real mortgage payments obtained as the residuals of the first stage regressions in the IV estimation. The columns differ in the way the cohorts of homeowners and renters are defined. In (i) and (iv) homeowners (renters) in quarter $t$ are those who reported being homeowners (renters) in quarter $t$. In (ii) and (v) homeowners (renters) are those who reported being homeowners (renters) in quarter $t$ and who reported living at their current address for at least six months. In (iii) and (vi) homeowners (renters) are those who reported being homeowners (renters) in quarter $t$ and who reported living at their current address for at least six months. In addition in (iii) and (vi) we classify as renters those who reported being homeowners who live at the present address for less than six months and who are younger than 32 years of age. Standard errors are shown in parentheses. The standard errors are corrected for first order serial correlation and heteroscedasticity. 
Table A.5: House Size Choices in Simulated Data

\begin{tabular}{|c|c|c|}
\hline & (i) & (ii) \\
\hline \multicolumn{3}{|c|}{ Panel A: Dependent Variable Renter-Homeowner } \\
\hline \multirow[t]{2}{*}{ Income } & 0.063 & 0.078 \\
\hline & $(0.004)$ & $(0.004)$ \\
\hline \multirow[t]{2}{*}{ Financial savings } & 0.217 & 0.032 \\
\hline & $(0.011)$ & $(0.001)$ \\
\hline \multirow[t]{2}{*}{$\Delta p_{t}$} & -1.651 & -2.285 \\
\hline & $(0.345)$ & $(0.321)$ \\
\hline \multicolumn{3}{|c|}{ 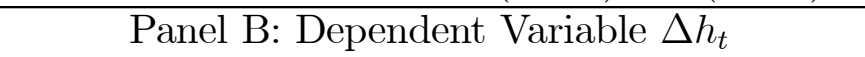 } \\
\hline \multirow[t]{2}{*}{$\Delta y_{t}$} & -0.011 & -0.007 \\
\hline & $(0.002)$ & $(0.001)$ \\
\hline \multirow[t]{2}{*}{$\Delta y_{t} \times$ Young Homeowner } & 0.068 & 0.069 \\
\hline & $(0.004)$ & $(0.005)$ \\
\hline \multirow[t]{2}{*}{$\Delta y_{t} \times$ Young Renter } & 0.744 & 0.614 \\
\hline & $(0.010)$ & $(0.009)$ \\
\hline \multirow[t]{2}{*}{$\Delta y_{t} \times$ Old Renter } & 0.561 & 0.244 \\
\hline & $(0.011)$ & $(0.016)$ \\
\hline \multirow[t]{2}{*}{$\Delta p_{t}$} & 0.084 & 0.063 \\
\hline & $(0.007)$ & $(0.008)$ \\
\hline \multirow{2}{*}{$\Delta p_{t} \times$ Young Homeowner } & -0.247 & -0.232 \\
\hline & $(0.014)$ & $(0.015)$ \\
\hline \multirow[t]{2}{*}{$\Delta p_{t} \times$ Young Renter } & -0.515 & -0.469 \\
\hline & $(0.027)$ & $(0.030)$ \\
\hline \multirow[t]{2}{*}{$\Delta p_{t} \times$ Old Renter } & -0.391 & -0.180 \\
\hline & $(0.033)$ & $(0.039)$ \\
\hline \multirow[t]{2}{*}{ Renter-Homeowner } & -0.214 & -0.172 \\
\hline & $(0.006)$ & $(0.007)$ \\
\hline
\end{tabular}


Note to Table A.5: The dependent variable in Panel A is a dummy variable that takes the value of one in periods in which the household switches from renting to owning, and zero otherwise. The independent variables include household income, financial savings, and the growth in house prices $(\Delta p)$. The dependent variable in Panel $\mathrm{B}$ is $\Delta h_{t}$, where $h$ is the log of real house size. The independent variables include the growth in household income, growth in house prices $(\Delta p)$, growth in income and house prices interacted with dummy variables for young homeowners, young renters, and old renters. Young are those younger than 40 years of age. Old are those older than 40 years of age, but younger than 60 years of age. We also include as independent variables a second order polynomial of age (estimated coefficients not reported). In columns (i) the data were generated by the model with 70 percent of the households facing the baseline parameters shown in Table 6 , and the remaining 30 percent facing the same parameters except for a lower discount factor equal to 0.85. In column (ii) the data were generated by the model with 70 percent of the households facing the baseline parameters shown in Table 6 , and the remaining 30 percent facing the same parameters except for a higher moving probability equal to 0.10. We estimate jointly the decision to become a homewoner, and the impact of house price changes on house size. Both equations include as independent variables a second order polynomial on age. 
Figure 1: Interest Rate, Inflation, and House Prices in the United Kingdom

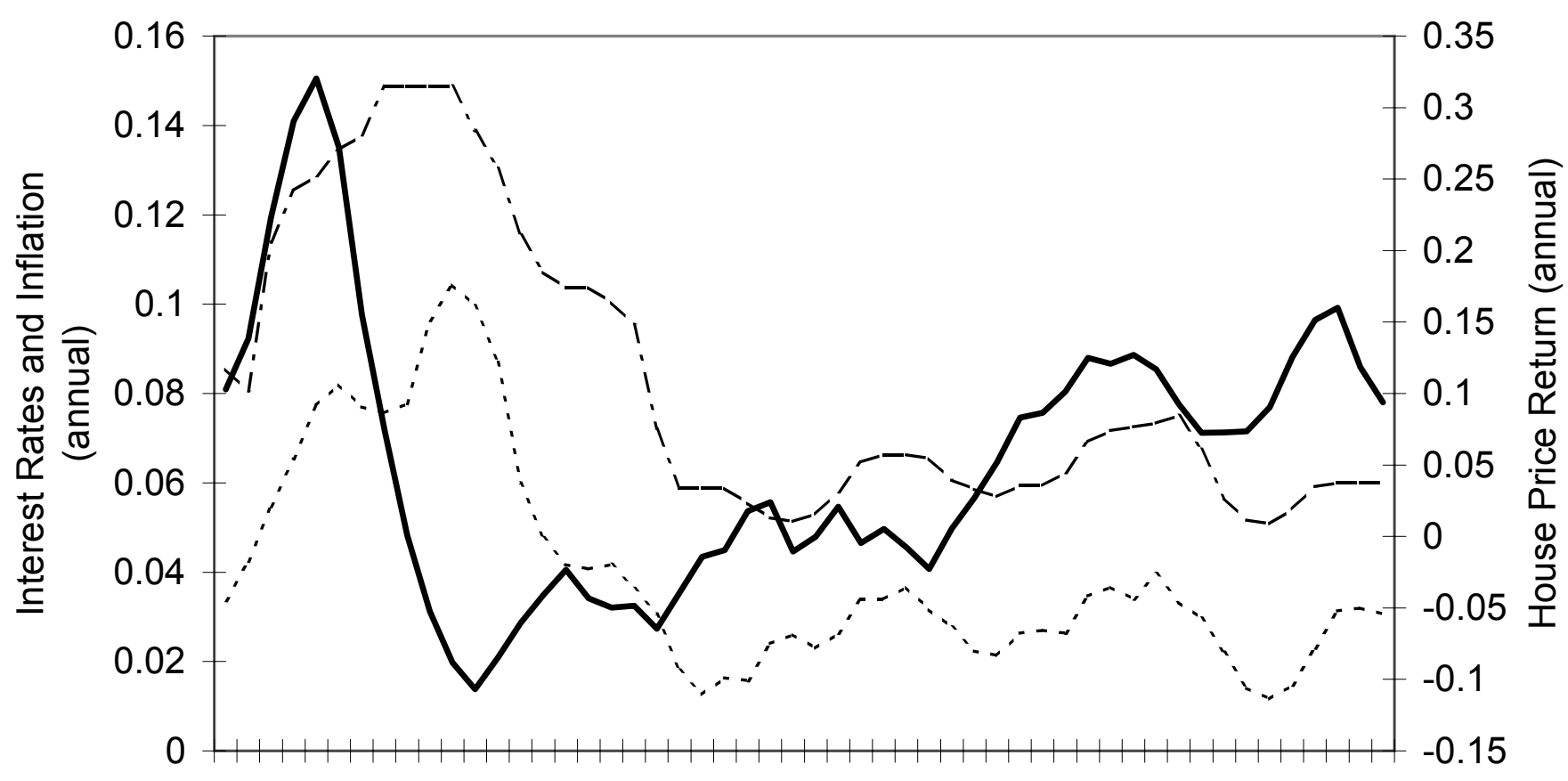

$\begin{array}{lllllllllllll}\text { Q1 } & \text { Q1 } & \text { Q1 } & \text { Q1 } & \text { Q1 } & \text { Q1 } & \text { Q1 } & \text { Q1 } & \text { Q1 } & \text { Q1 } & \text { Q1 } & \text { Q1 } & \text { Q1 }\end{array}$

1988198919901991199219931994199519961997199819992000

Year

- - - Nominal Interest Rate -...-. Inflation —-Nominal House Price Return

Note to Figure 1: This figure shows nominal interest rates, inflation rate and house price return for the United Kingdom. The inflation rate measure is the change in the Retail Price Index. The house price data is from Nationwide. The series are quarterly, but are in annual terms. 
Figure 2: Non Durable Consumption and Income Over the Life Cycle

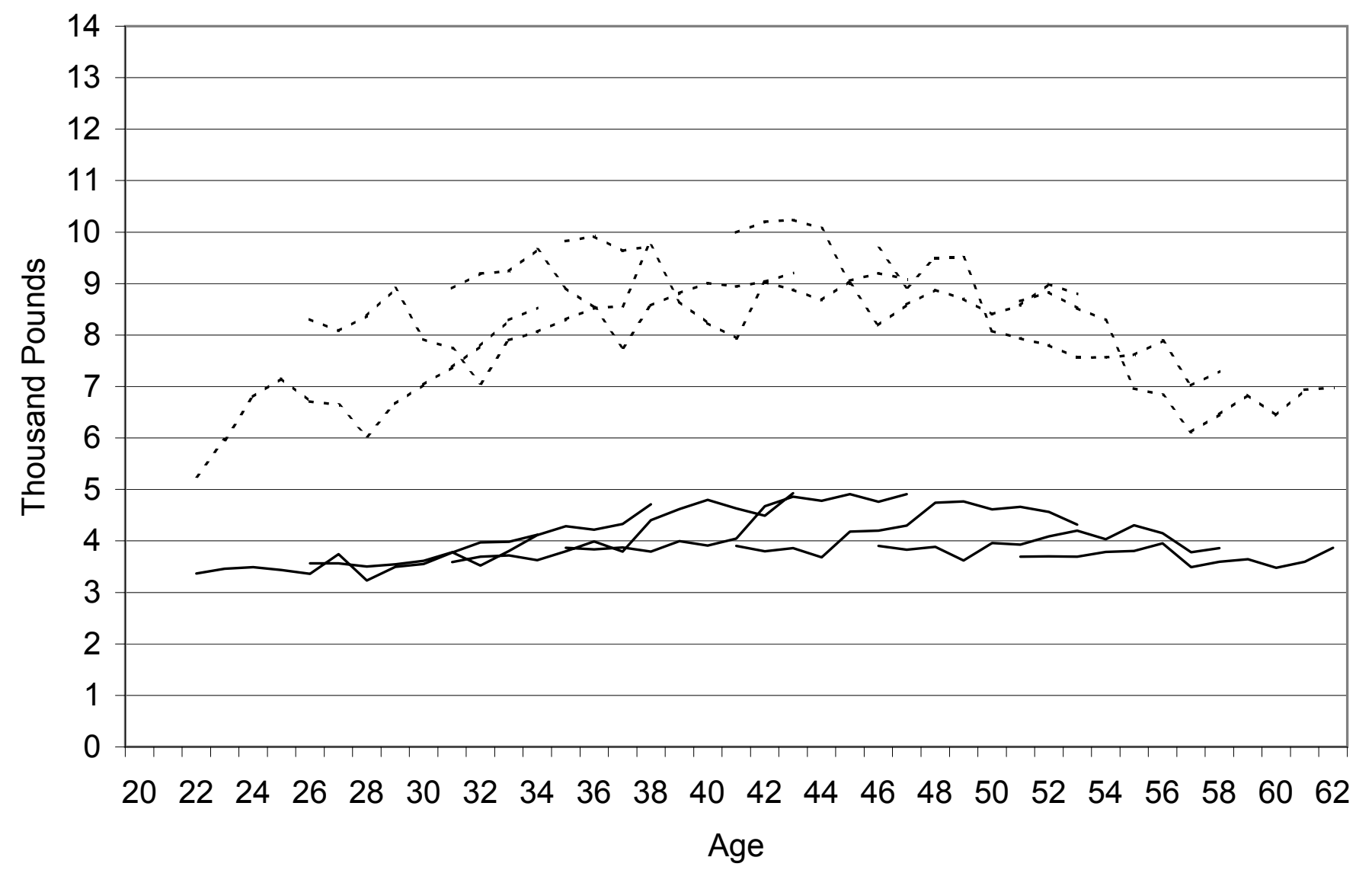

Note to Figure 2: This figure plots annual real non-durable consumption (solid line) and real income (dashed linı over the life-cycle for different cohorts. The data is from the UK Family Expenditure Survey. The age-cohort income and consumption were obtained by regressing consumption and income on year-cohort dummies. Annual values were obtained by multiplying the two week consumption and income by twenty six. 
Figure 3: Non Durable Consumption and Income Over the Life Cycle for Homeowners

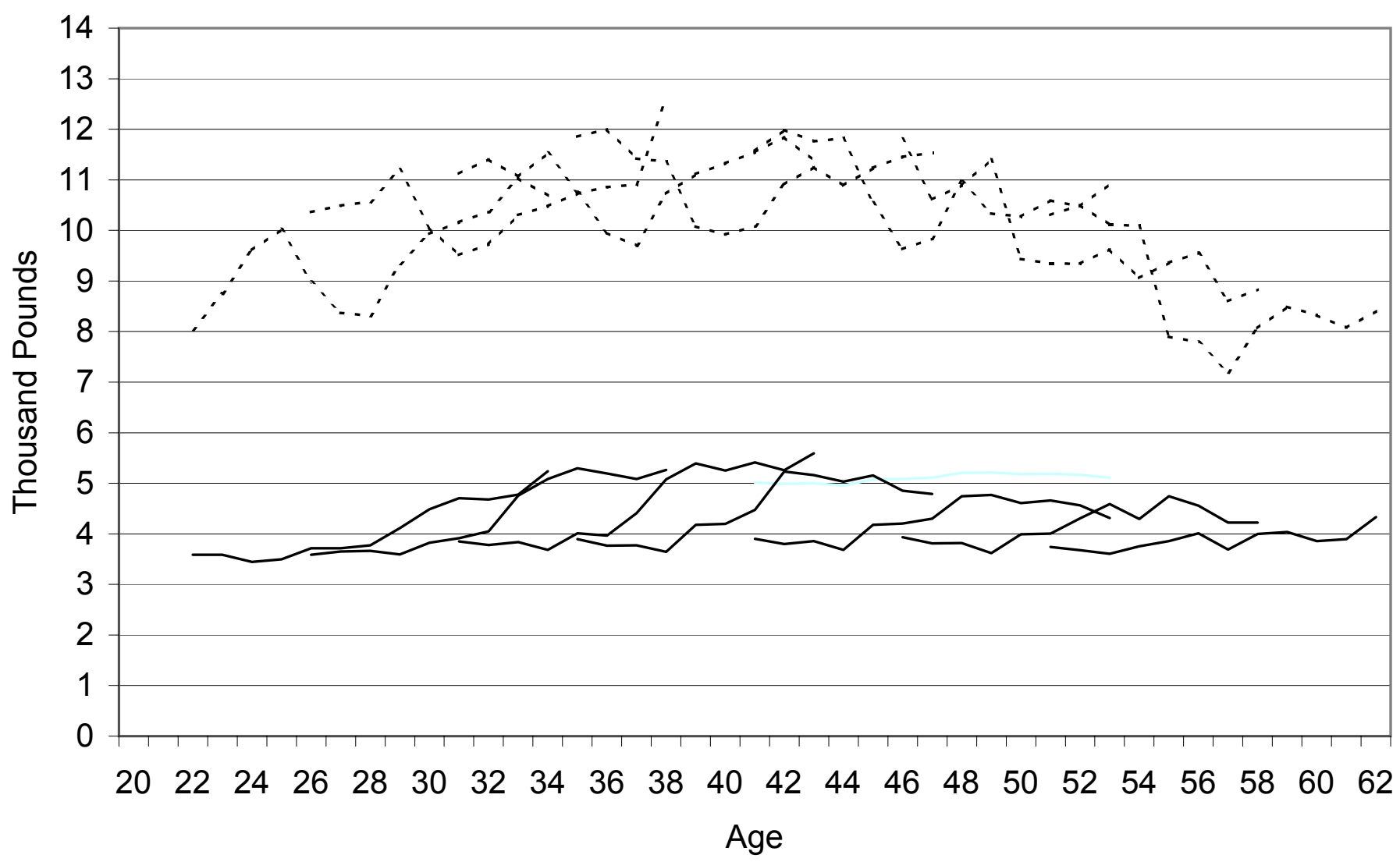

Note to Figure 3: This figure plots annual real non-durable consumption (solid line) and real income (dashed lin over the life-cycle for different cohorts, and with the sample restricted to homeowners. The data is from the UK Family Expenditure Survey. The age-cohort income and consumption were obtained by regressing consumptior and income on year-cohort dummies. Annual values were obtained by multiplying the two week consumption ar income by twenty six. 
Figure 4: Proportion of Renters (dashed), Owners with Mortgage (solid), and Owners Outright

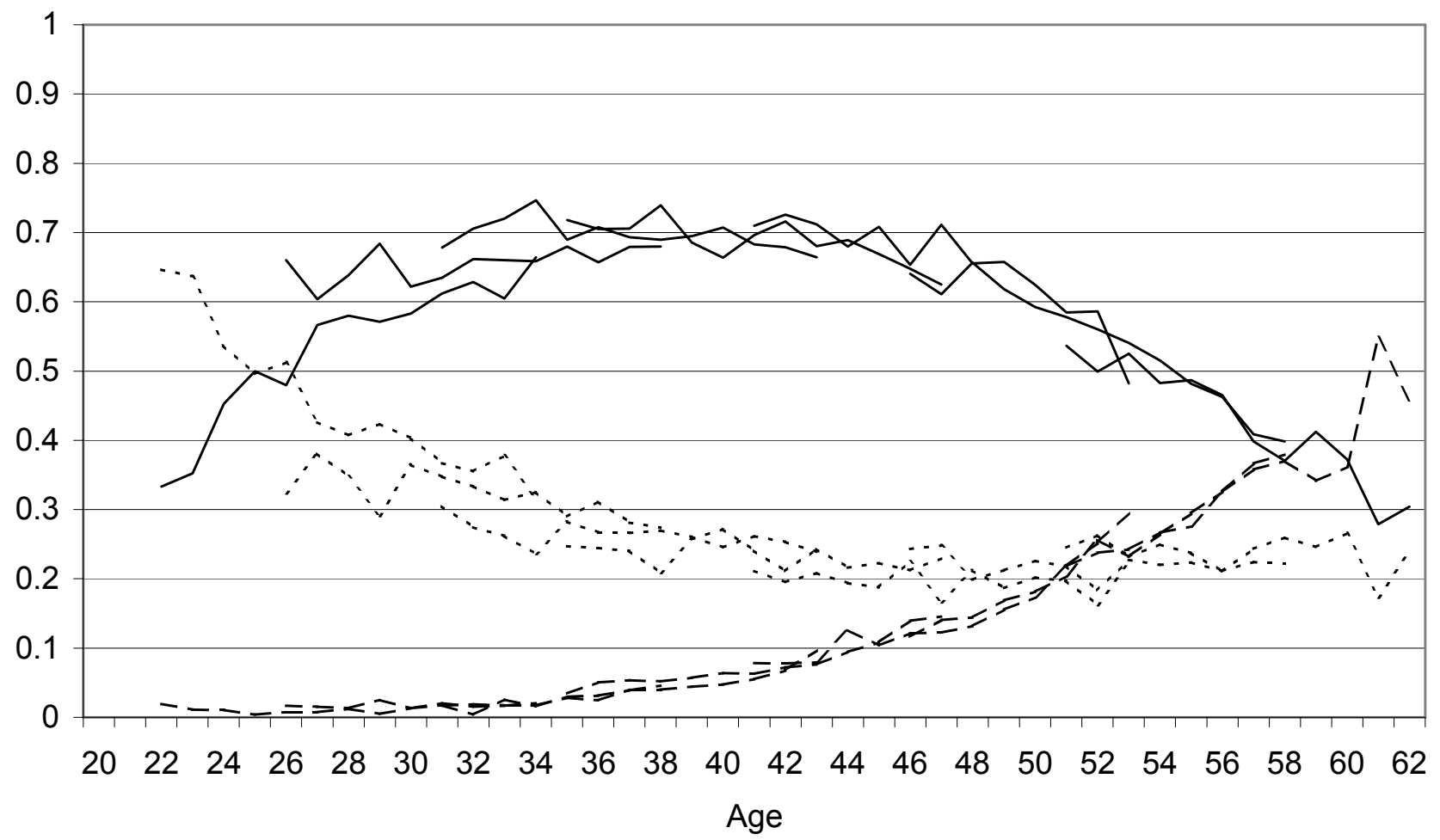

Note to Figure 4: This figure plots the proportion of renters, homeowners with mortgage, and owners outright over the life-cycle for different cohorts. The data is from the UK Family Expenditure Survey for the years 1988 to 2000 . 
Figure 5: Mortgage Payments Over the Life Cycle

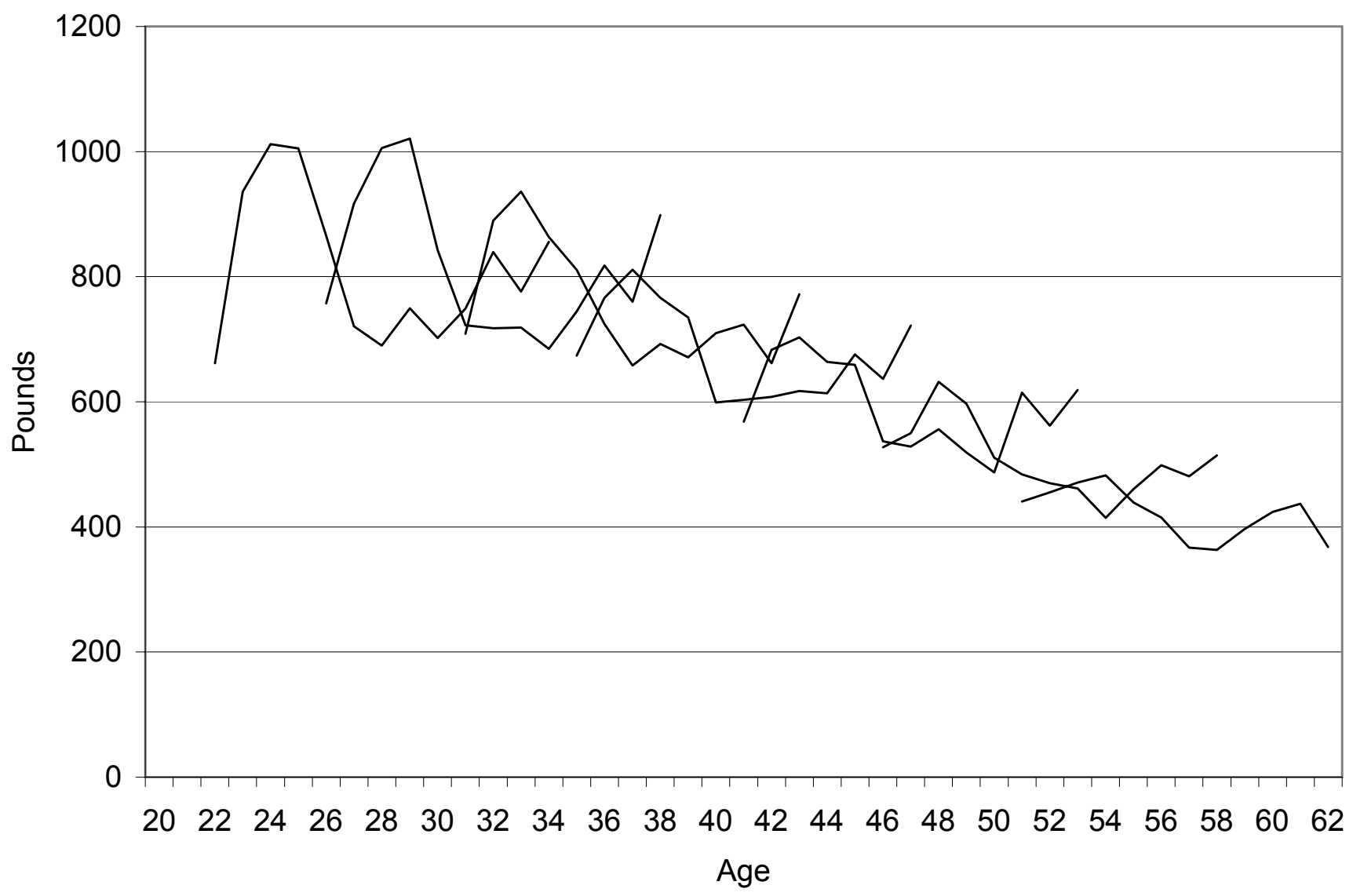

Note to Figure 5: This figure plots annual real mortgage payments over the life-cycle for mortgage holders, and for different cohorts. The data is from the UK Family Expenditure Survey for the years 1988 to 2000. 
Figure 6: Regional House Prices in The United Kingdom

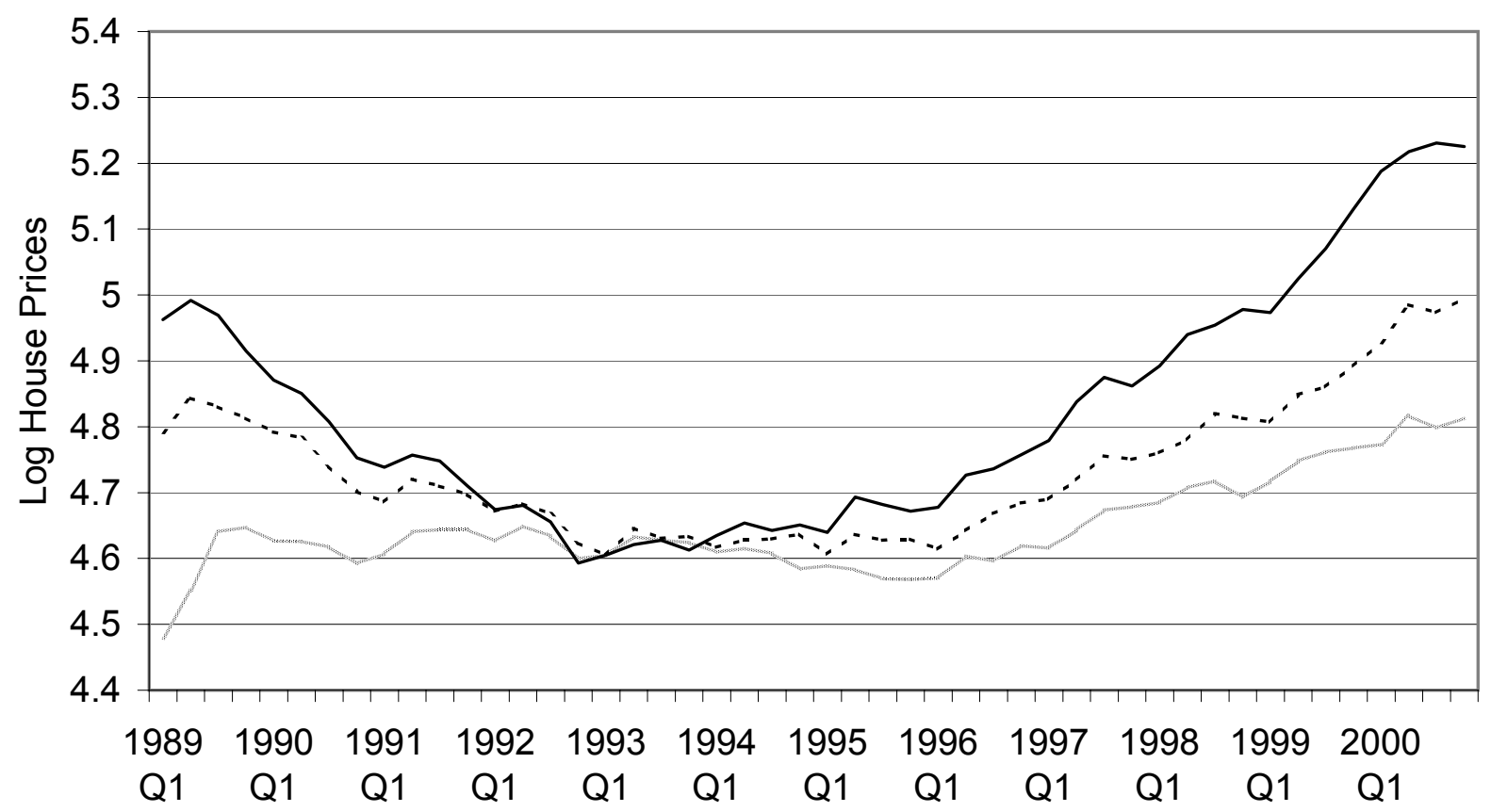

Cohorts N1 - N3 -... - Cohorts C1 - C3 —- Cohorts S1 - S3

Note to Figure 6: This figure shows the evolution of house prices in the three UK regions that we consider: North, Center, and South.

North: Scotland, North West, North East, Yorkshire and Humberside.

Center: East Midlands, West Midlands, Wales, Eastern Anglia.

South: South East, South West, London. 